\title{
Optimal taxation under equilibrium unemployment and economic profits
}

\author{
Wei Jiang* \\ University of Kent
}

18 Febuary 2018

\begin{abstract}
This paper develops a heterogeneous agent model with equilibrium unemployment and economic profits due to productive public investment. We find that the presence of profits plays an important role in the determination of long-run optimal tax policy. The Judd-Chamley optimal zero capital tax result can still hold in the model without profits. In this case, the optimal wedge is zero in the long run, resulting in welfare gains for all agents and no conflict of interests between agents. But the Benthamite government chooses to subsidise capital income in the long run in the model with economic profits. The resulting labour wedge is non-zero which generates welfare losses of workers despite welfare gains of capitalists. The government also faces a trade-off between efficiency and equity in this case.

Keywords: household heterogeneity, equilibrium unemployment, economic profits, optimal taxation
\end{abstract}

JEL codes: E13, E22, E62

*Address for correspondence: Wei Jiang, School of Economics, Keynes College, University of Kent, Canterbury, CT2 7NP. E-mail: w.jiang@kent.ac.uk. I would like to thank Konstantinos Angelopoulos, Jagjit Chadha, Jilei Huang, Miguel León-Ledesma, James Malley, and participants and discussants at the University of Glasgow seminar, University of Kent Internal Workshop, China Meeting of the Econometric Society in Beijing and Royal Economic Society Annual Conference at Manchester. I would also like to thank the anonymous referee for helpful comments and suggestions. The remaining errors are mine. 


\section{Introduction}

Since the 1980s there has been an extensive literature studying optimal taxation in macroeconomics. For example, Chamley (1986) studies optimal taxation using a representative agent model. He shows that the government should use a zero tax rate on capital income in the long run. Chari et al. (1994) and Chari and Kehoe (1999) also conclude that a permanent positive tax rate on capital income is not efficient in a Ramsey-type setup of the government. Whether capital income should be taxed or not in the long run still remains an open question in the literature. For instance, Correia (1996) has suggested that the optimal capital tax should be different from zero if there are restrictions on the taxation of production factors. Guo and Lansing (1999) introduce imperfect competition and profits in the product market and they show that the optimal zero capital tax rate might not be obtained in the long run assuming that the government has access to a commitment technology. The introduction of profits via firms' monopoly power creates capital market distortions which break down the normative result of optimal zero capital income tax. Koskela and von Thadden (2008) model the non-Walrasian labour market with Nash bargaining between firms and labour unions. They suggest that both capital and labour taxes should be used in the long run. Also the result of non-zero optimal capital income tax can be obtained in the models without commitment technology for the government (see e.g. Krusell (2002) and Angelopoulos et al. (2011)). All these studies have shown the importance of economic structure in determining optimal taxation.

This family of models, however, is silent on the research question of inequality which has resulted from the conflict of interests between different agents. Heterogeneous agent models obviously become a good candidate for studying the distributional effect of optimal taxation. Within the heterogeneous agent framework, the seminal research of Judd (1985) makes a distinction between "capitalists" and "workers" in order to investigate the redistributive potential of capital taxation. He suggests that the optimal tax policy under commitment is not to tax capital income in the long run and to raise all the required tax revenues by taxing labour income. This result holds even when the government cares only about workers. This implies that there is no conflict of interests between agents. More recent literature including Werning (2007), Conesa et al. (2009), Angelopoulos et al. (2017) and Asimakopoulos and Asimakopoulos (2017) have studied optimal fiscal policy under different assumptions about agent heterogeneity. The distinction of our paper to theirs is the inclusion of unemployment on the workers' side. In our setting with unemployment, the government chooses optimally 
not only labour income taxes, but unemployment benefits. This creates a new channel for governments to set their optimal fiscal policies that could, potentially, change the optimal tax mix. Changes in unemployment benefits will change workers incentives to supply labour, affecting their welfare and having distributional consequences.

This paper uses a heterogeneous agent general equilibrium model to examine the effects of optimal taxation on unemployment, the distribution of income, and welfare of agents in the economy. We stay as close as possible to Judd (1985), but two new elements are introduced into their model: equilibrium unemployment and productive public investment resulting in profits of firms. In addition, this study sheds some light on the determination of optimal labour wedge which captures the gap between the marginal rate of substitution between leisure and consumption, and the marginal product of labour. The optimal determination of labour wedge is studied in Arsenau and Chugh (2012). Their focus is on optimal 'wedge smoothing' over the business cycles using frictional labour markets. Our analysis is focused on how the market structure can affect the optimal labour wedge in the long run. In a competitive labour market, unemployment is generated, following for example, Pissarides (1998), Ardagna (2001) and Ljungqvist and Sargent (2006), as the outcome of optimal choices made by workers. This paper extends their model by allowing for agent heterogeneity given different economic roles of agents in the economy. Following Judd (1985), Lansing (1999) and Ardagna (2007), we assume that capitalists do not work and workers do not save. In this setup, the government taxes labour income and interest income from capital and profits to finance its public spending. The unemployment benefits in this model mimic the role that they have in a non-competitive labour market. ${ }^{1}$ An increase in unemployment benefits tends to decrease the labour supply of workers and then put some pressure on the equilibrium wage rate. Alternatively, unemployment benefits can be considered as another tax rate on labour income. By separating unemployment benefits from the explicit tax rate on labour income, it is possible to investigate the different effects of these two policy instruments on workers and government's budget.

Following Lansing (1999) and Malley et al. (2009), we assume that the government can provide individual firms with public capital without asking for rents. The production is constant-returns-to-scale (CRTS) in three productive inputs: private capital, labour and public capital. The equilibrium profits are equal to the difference between the value of output and the pro-

\footnotetext{
${ }^{1}$ Unemployment can also be generated in the unionised labour market (see e.g. Maffezzoli (2001) and Ardagna (2007)), or in the model with search frictions (see e.g. Mortensen and Pissarides (1994) and Pissarides (2001)).
} 
duction costs of inputs employed in the private sectors. This setup allows us to examine the relevance of profits in determining the optimal taxation of a Benthamite (non-partisan) government. The case of partisan government is also examined, in the sense that the government is biased towards one agent and places higher weight on the welfare of that agent in its objective function. In order to understand the role played by profits in determining the optimal policy, we also analyze a version of the model without public investment and, hence, without profits.

The model with exogenous policy instruments is calibrated so that its steady state can reflect the main empirical characteristics of the UK economy. The main findings can be summarized as follows. First, in the model with zero profits, we find that the optimal tax rate on capital income is zero in the long run. The government chooses to tax the leisure of workers. This is equivalent to a subsidy to the labour supply of workers. Meanwhile, the government slightly increases the tax rate on labour income. We also find that the distortions in the labour market caused by the labour income tax can be completely eliminated as a consequence of the equal amount of government subsidies to the workers in the form of taxation on leisure. In other words, the positive effect of the negative replacement rate and the negative effect of the increase in labour tax on workers net out in the long run. Therefore, the gap between the marginal rate of substitution between leisure and consumption and the marginal product of labour disappears. As a result, the labour supply of workers increases which is beneficial to workers. The income, consumption and welfare of workers improves. In addition, as in Judd (1985), the results further show that optimal taxation and allocation under commitment are independent of the weight on the welfare of the agent in the Ramsey setup of the government. This implies that there is no conflict of interests between agents in the long run.

Second, the result of long-run optimal zero capital tax cannot be obtained in the model with non-zero economic profits due to the presence of productive public investment. The optimal tax rate on capital income is negative which means the government chooses to subsidise the capital income in the long run. There are two opposing effects in determining the sign of optimal capital income tax: under-investment effect and profit effect. In our model, on the one hand, the crowding-out effect of public investment is equivalent to the under-investment effect which motivates a Benthamite government to use a subsidy to capital income in order to reduce distortions in the capital market. On the other hand, the presence of profits motivates the government to use a positive tax rate on capital income as taxing profits is not distortionary. In our case, we show that the under-investment effect outweighs the profit effect. As a result, the government subsidises the capital income in the long 
run. The optimal capital tax directly increases the investment of capitalists and therefore the income, consumption and welfare of capitalists increase. In the labour market, the government subsidises the labour supply of workers while the tax rate on labour income slightly increases. These two policy instruments have opposing effects on the labour supply of workers. We find that the positive effect of labour subsidy dominates so that the labour supply of workers is higher than it would be in the model with exogenous policy. In this model, there is a gap between the marginal rate of substitution between leisure and consumption, and the marginal product of labour, so that the tax distortion in the labour market cannot be completely eliminated in the long run. The distortion causes welfare losses for workers. We further find that the weight on the welfare of agents matters for the optimal taxation. This implies that the optimal taxation generates conflict of interests between agents and it has redistributional effects. As the weight on the welfare of capitalists increases, the capital taxation decreases and it turns into a subsidy after a critical value. The tax rate on labour income increases in order to make up for the losses in government's tax revenues. In this case, a trade-off between efficiency and equity needs to be taken into account by the government in policy-making decision.

The rest of this paper is organised as follows: Section 2 sets out the model structure, the calibration to the UK economy and steady-state of the model given exogenous policy; Section 3 analyses the optimal policy under commitment; Section 4 finally offers a summary and conclusion.

\section{The model}

The main features of the economy are summarised as follows. Infinitely lived households, firms, and a government populate the economy. There is a large but fixed number of households which can be divided into two types in terms of their different roles in the economy: capitalists and workers. Following Judd (1985), Lansing (1999) and Ardagna (2007), capitalists by assumption do not work and workers do not save. Capitalists can participate in the capital market and they are owners of firms. Their income includes interest income from private capital and dividends of firms. Employed workers supply labour to the firms and obtain wage incomes. If workers are unemployed, they can receive unemployment benefits from the government. Workers consume all their disposable income in each period. We don't examine worker heterogeneity in the model so that all the workers get the same average income. Following Pissarides (1998), Ardagna (2001) and Ljungqvist and Sargent (2006), equilibrium unemployment is generated in the competitive 
labour market as the outcome of optimal choices made by workers. Firms are perfectly competitive and they produce a single product in the goods sector with a constant-returns-to-scale technology in private capital, labour and public capital. When there is public investment in the production function, profits arise in this economy. ${ }^{2}$ Finally, the government purchases goods and services from the private sector which could enhance the utility of households. It provides unemployment benefits to unemployed workers and public capital to final goods production. The government finances all its spending requirements by taxing labour income and interest income from capital and profits.

\subsection{Population composition}

The population size of households is given by $N$. The population sizes of capitalists and workers are assumed to be: $N^{k}$ and $N^{w}{ }^{3}$ The population shares of capitalists and workers are assumed to be: $N^{k} / N \equiv n^{k}$, and $N^{w} / N \equiv n^{w}=1-n^{k}$. The population composition is taken as given and fixed over time. Each capitalist owns one single firm. This implies that the number of firms is equal to the number of capitalists, i.e. $N^{f}=N^{k}$.

\subsection{Capitalists}

The utility function of households is of the constant elasticity of substitution (CES) variety which is defined over a composite good and leisure as follows:

$$
U_{t}^{i}=\left[\mu\left(C_{t}^{i}+\omega \bar{G}_{t}^{c}\right)^{\frac{\sigma-1}{\sigma}}+(1-\mu)\left(1-H_{t}^{i}\right)^{\frac{\sigma-1}{\sigma}}\right]^{\frac{\sigma}{\sigma-1}}
$$

where $C_{t}^{i}$ is household $i$ 's private consumption; $\bar{G}_{t}^{c}$ represents per capita government consumption, i.e. $\bar{G}_{t}^{c}=G_{t}^{c} / N$, where $G_{t}^{c}$ denotes aggregate government consumption; $H_{t}^{i}$ is the labour supply. We fix $H_{t}^{k}=0$ for the capitalists in their utility function as they are assumed to not work in the economy. The parameter $\sigma>0$ measures the elasticity of substitution between consumption and leisure; and $0<\mu<1$ is the weight given to consumption relative to leisure in the utility.

\footnotetext{
${ }^{2}$ Although this paper focuses on the effects of public investment on optimal policy, as a robustness check we also considered profit generation along the lines of Guo and Lansing (1999). In that case, profits are generated as a consequence of monopolistic competition among firms. The optimal policy results are shown to be robust to what we have found in our paper. The model derivation and results are available upon request.

${ }^{3}$ Variables for capitalists are indexed by the superscript $k$ and variables for workers are indexed by the superscript $w$ in what follows. Finally, the firms are indexed by the superscript $f$.
} 
The utility function differs from the conventional neoclassical utility function by including the term of per capita government consumption, $\bar{G}_{t}^{c}$. The private consumption and government consumption are assumed to be substitutes in the utility function. The degree of substitutability is determined by the constant parameter $0<\omega \leq 1$. In this way, the government could affect households via the utility effect of $\bar{G}_{t}^{c}$. Barro (1981 and 1989) suggests that government consumption expenditure on goods and services can provide direct utility for the households. This argument is supported by some empirical studies in the literature. Kormendi (1983) and Aschauer (1985) test the parameter which defines the relationship between private and government consumption for the US economy, and Ahmed (1986) for the UK economy. They all support the substitutability relationship. This specification of substitutability between private and government consumption is widely used in the RBC literature. ${ }^{4}$

The objective function of the representative capitalist is to maximise his present discounted value of lifetime utility:

$$
\max \sum_{t=0}^{\infty} \beta^{t} U_{t}^{k}\left(C_{t}^{k}, \bar{G}_{t}^{c}\right)
$$

where $0<\beta<1$ is the constant discount factor and $U_{t}^{k}$ is given by:

$$
U_{t}^{k}=\left[\mu\left(C_{t}^{k}+\omega \bar{G}_{t}^{c}\right)^{\frac{\sigma-1}{\sigma}}+(1-\mu)(1-0)^{\frac{\sigma-1}{\sigma}}\right]^{\frac{\sigma}{\sigma-1}} .
$$

The budget constraint of each capitalist at time $t$ is given by:

$$
C_{t}^{k}+I_{t}^{k}=r_{t} K_{t}^{k}-\tau_{t}^{k}\left(r_{t}-\delta^{p}\right) K_{t}^{k}+\left(1-\tau_{t}^{k}\right) \pi_{t}^{k}
$$

where $K_{t}^{k}$ is the private capital stock at the beginning of time $t ; I_{t}^{k}$ is the investment; $r_{t}$ is the gross return to capital; $\pi_{t}^{k}$ denotes profits; $0<\delta^{p}<1$ is the constant depreciation rate of capital stock; and $0 \leq \tau_{t}^{k}<1$ is the tax rate on capital income and profits. ${ }^{5}$

The evolution equation of capital stock is:

$$
K_{t+1}^{k}=\left(1-\delta^{p}\right) K_{t}^{k}+I_{t}^{k}
$$

\footnotetext{
${ }^{4}$ See Aschauer and Greenwood (1985), Ambler and Paquet (1996) and Finn (1998).

${ }^{5}$ Following Guo and Lansing (1999), we assume that the government cannot distinguish between returns to capital stock and profits received from firms, so that they are taxed at the same rate. In addition, the capital taxes are assumed to be net of depreciation (see e.g. Lansing (1999)).
} 
The capitalist chooses $\left\{C_{t}^{k}, K_{t+1}^{k}\right\}_{t=0}^{\infty}$ to maximize (2) subject to the constraints (3), (4) and (5) by taking market prices $\left\{r_{t}\right\}_{t=0}^{\infty}$, policy variables $\left\{\tau_{t}^{k}, \bar{G}_{t}^{c}\right\}_{t=0}^{\infty}$ and an initial condition for the capital stock, $K_{0}^{k}$, as given. ${ }^{6}$

The optimality condition of the capitalist:

$$
\begin{aligned}
& \left(C_{t}^{k}+\omega \bar{G}_{t}^{c}\right)^{-\frac{1}{\sigma}}\left[\mu\left(C_{t}^{k}+\omega \bar{G}_{t}^{c}\right)^{\frac{\sigma-1}{\sigma}}+(1-\mu)\right]^{\frac{1}{\sigma-1}} \\
= & \beta\left(C_{t+1}^{k}+\omega \bar{G}_{t+1}^{c}\right)^{-\frac{1}{\sigma}}\left[\mu\left(C_{t+1}^{k}+\omega \bar{G}_{t+1}^{c}\right)^{\frac{\sigma-1}{\sigma}}+(1-\mu)\right]^{\frac{1}{\sigma-1}} . \\
& \left.\cdot\left[1+\left(1-\tau_{t+1}^{k}\right)\left(r_{t+1}-\delta^{p}\right)\right]\right\} .
\end{aligned}
$$

This is the consumption Euler equation of capitalists which describes the optimal intertemporal choice made by capitalists in equilibrium. It implies that the marginal utility of foregone consumption at time $t$ should be equal to the expected marginal benefit of discounted $t+1$ returns from investing one more unit at time $t$ in equilibrium.

\subsection{Workers}

The workers are assumed to be identical in the labour market. Hence, the labour supply of workers to firms is homogenous. They work and consume all their disposable income in each period. Unemployment is generated in the competitive labour market as the outcome of optimal choices made by the workers. Time off work is then treated as unemployment in the model. If unemployed, workers receive unemployment benefits from the government. The time constraint of workers is crucial in the workers' setup. It is described as follows. At time $t$, the workers are endowed with the fixed amount of time. The time spent on physiological needs is treated as the exogenous leisure of workers. Apart from this, the workers are expected to work for the firms and obtain wage income from working. This portion of time is taken as potential labour supply of workers which is normalised to unity. In the competitive labour market, both firms and workers are assumed to be price takers. The wage rate is determined when the aggregate labour supply is equal to the aggregate labour demand. The equilibrium labour supply generated by the model is less than the potential labour supply of workers. The difference between these two is then treated as unemployment. In other words, time off work is considered as unemployment in this model. Unemployment by assumption could generate both leisure and unemployment benefits for the workers. The structural parameters is calibrated so that per capita unemployment benefits are always below the net return to labour. In other words,

\footnotetext{
${ }^{6}$ The utility-maximisation problem of the capitalist is given in Appendix - 1 .
} 
leisure is costly to workers as working can generate higher labour income. The workers do not save so that they do not have to make intertemporal choices. The optimization problem for the workers is thus static.

At time $t$, the objective function of the representative worker is given by:

$$
\max U_{t}^{w}\left(C_{t}^{w}, 1-H_{t}^{w}, \bar{G}_{t}^{c}\right)
$$

and the utility function is:

$$
U_{t}^{w}=\left[\mu\left(C_{t}^{w}+\omega \bar{G}_{t}^{c}\right)^{\frac{\sigma-1}{\sigma}}+(1-\mu)\left(1-H_{t}^{w}\right)^{\frac{\sigma-1}{\sigma}}\right]^{\frac{\sigma}{\sigma-1}} .
$$

The time constraint of the worker is given by:

$$
L_{t}^{w}=1-H_{t}^{w}
$$

where $L_{t}^{w}$ denotes the leisure of the worker.

The worker has the following within-period budget constraint:

$$
C_{t}^{w}=\left(1-\tau_{t}^{w}\right) w_{t} H_{t}^{w}+\bar{G}_{t}^{u}\left(1-H_{t}^{w}\right)
$$

where $w_{t}$ is the wage rate; $0 \leq \tau_{t}^{w}<1$ is the tax rate on labour income; and $\bar{G}_{t}^{u}$ is per capita unemployment benefits which are assumed to be proportional to the wage rate, i.e. $\bar{G}_{t}^{u}=\bar{r}_{t} w_{t}$, where $0 \leq \bar{r}_{t}<1$ is the replacement rate measuring the imputed value of leisure. As discussed above, unemployment benefits are less than the net wage rate, i.e. $\bar{r}_{t} w_{t}<\left(1-\tau_{t}^{w}\right) w_{t}$, so that unemployment is costly to the worker although it yields leisure.

The value of the free parameter in the utility function, $\mu$, is calibrated, such that the model's steady-state unemployment is in line with the data average between 1970 and 2009. ${ }^{7}$

At time $t$, the worker takes the market price, $w_{t}$, per capita government consumption and unemployment benefits, $\bar{G}_{t}^{c}$ and $\bar{G}_{t}^{u}$, and the tax rate on labour income, $\tau_{t}^{w}$, as given, and chooses $C_{t}^{w}$ and $H_{t}^{w}$ to maximize (7) subject to the constraints (8), (9) and (10). ${ }^{8}$

The optimality condition of the worker is:

$$
\begin{aligned}
& (1-\mu)\left(1-H_{t}^{w}\right)^{-\frac{1}{\sigma}}+\mu \bar{r}_{t} w_{t}\left(C_{t}^{w}+\omega \bar{G}_{t}^{c}\right)^{-\frac{1}{\sigma}} \\
= & \mu w_{t}\left(1-\tau_{t}^{w}\right)\left(C_{t}^{w}+\omega \bar{G}_{t}^{c}\right)^{-\frac{1}{\sigma}}
\end{aligned}
$$

by replacing $\bar{G}_{t}^{u}$ with $\bar{r}_{t} w_{t}$.

\footnotetext{
${ }^{7}$ In the UK economy, the average of unemployment rate was $7 \%$ between 1970 and 2009.

${ }^{8}$ The utility-maximisation problem of the worker is given in Appendix - 2 .
} 
The expression above is re-arranged to obtain the following condition:

$$
1-\tau_{t}^{w}-\bar{r}_{t}=\frac{\frac{(1-\mu)\left(1-H_{t}^{w}\right)^{-\frac{1}{\sigma}}}{\mu\left(C_{t}^{w}+\omega \bar{G}_{t}^{c}\right)^{-\frac{1}{\sigma}}}}{w_{t}}
$$

where $\frac{(1-\mu)\left(1-H_{t}^{w}\right)^{-\frac{1}{\sigma}}}{\mu\left(C_{t}^{w}+\omega \bar{G}_{t}^{c}\right)^{-\frac{1}{\sigma}}}=M R S_{H_{t}^{w}, C_{t}^{w}}$ is the marginal rate of substitution between leisure and consumption. Therefore, the r.h.s. of the equation reflects the gap between the marginal rate of substitution between leisure and consumption, and the marginal product of labour. ${ }^{9}$ Chari et al. (2002 and 2007a) and Shimer (2009) define it as the labour wedge. The labour wedge is interpreted as an indicator of the labour market distortions.

\section{$2.4 \quad$ Firms}

The government can invest in the production of goods. The government provides individual firms with public capital without asking for rents. Following Lansing (1999) and Malley et al. (2009), the firm produces homogeneous goods with a CRTS technology in labour, private capital and public capital. ${ }^{10}$ The production function of the representative firm is given by:

$$
Y_{t}^{f}=A\left(K_{t}^{f}\right)^{\alpha_{1}}\left(H_{t}^{f}\right)^{\alpha_{2}}\left(\bar{K}_{t}^{g}\right)^{\alpha_{3}}
$$

where $Y_{t}^{f}$ represents the firm's output; $K_{t}^{f}$ is the capital stock employed by the firm in the production; $H_{t}^{f}$ is the labour input; $\bar{K}_{t}^{g}$ denotes the per capita public capital which is exogenously provided by the government; $A$ is the constant technology level; and $0<\alpha_{1}, \alpha_{2}, \alpha_{3}<1$ denote the shares of output for the private capital, labour and public capital. The CRTS technology implies $\alpha_{1}+\alpha_{2}+\alpha_{3}=1 .^{11}$

The profits earned by the firm at time $t$ are given by: ${ }^{12}$

$$
\pi_{t}^{f}=Y_{t}^{f}-r_{t} K_{t}^{f}-w_{t} H_{t}^{f} .
$$

\footnotetext{
${ }^{9}$ In equilibrium, the firms hire the workers until the wage rate is equal to the marginal product of labour. This is shown in the profit-maximizing problem of the firm as follows.

${ }^{10}$ See Aschauer (1989), Munell (1990) and Ai and Cassou (1995). These empirical studies support for the specification of CRTS in these three inputs.

${ }^{11}$ In the policy analysis, we also consider the model without public investment and profits, so that $\alpha_{3}=0$ and $\alpha_{1}+\alpha_{2}=1$. In the calibration, the labour's share of output, $\alpha_{2}$, is calibrated to the average in the data.

${ }^{12}$ The price of goods is fixed to be 1 , so that all the variables in the model are written in real terms.
} 
At time $t$, the firm chooses the quantities of capital and labour in order to maximise profits taking the market prices of them as given. ${ }^{13}$

The profit maximisation gives the following two conditions:

$$
r_{t}=\alpha_{1} A\left(K_{t}^{f}\right)^{\alpha_{1}-1}\left(H_{t}^{f}\right)^{\alpha_{2}}\left(\bar{K}_{t}^{g}\right)^{\alpha_{3}}=\frac{\alpha_{1} Y_{t}^{f}}{K_{t}^{f}}
$$

and

$$
w_{t}=\alpha_{2} A\left(K_{t}^{f}\right)^{\alpha_{1}}\left(H_{t}^{f}\right)^{\alpha_{2}-1}\left(\bar{K}_{t}^{g}\right)^{\alpha_{3}}=\frac{\alpha_{2} Y_{t}^{f}}{H_{t}^{f}} .
$$

The profits are:

$$
\begin{aligned}
\pi_{t}^{f} & =Y_{t}^{f}-r_{t} K_{t}^{f}-w_{t} H_{t}^{f} \\
& =Y_{t}^{f}-\frac{\alpha_{1} Y_{t}^{f}}{K_{t}^{f}} K_{t}^{f}-\frac{\alpha_{2} Y_{t}^{f}}{H_{t}^{f}} H_{t}^{f} \\
& =\left(1-\alpha_{1}-\alpha_{2}\right) Y_{t}^{f} .
\end{aligned}
$$

In equilibrium, the firm earns strictly positive economic profits which are equal to the difference between the value of output and the production costs of inputs employed from the capitalists and workers.

\subsection{Government}

In the absence of government debt, ${ }^{14}$ the government has a balanced budget in each period. The budget constraint of the government is:

$$
\begin{aligned}
& N \bar{G}_{t}^{c}+N^{w} \bar{r}_{t} w_{t}\left(1-H_{t}^{w}\right)+N^{k} \bar{I}_{t}^{g} \\
= & N^{k}\left(\tau_{t}^{k}\left(r_{t}-\delta^{p}\right) K_{t}^{k}+\tau_{t}^{k} \pi_{t}^{k}\right)+N^{w} \tau_{t}^{w} w_{t} H_{t}^{w}
\end{aligned}
$$

where $\bar{I}_{t}^{g}$ is the per capita public investment.

The public capital stock, $\bar{K}_{t}^{g}$, evolves according to:

$$
\bar{K}_{t+1}^{g}=\left(1-\delta^{g}\right) \bar{K}_{t}^{g}+\bar{I}_{t}^{g}
$$

\footnotetext{
${ }^{13}$ The profit maximisation problem of the firm is given in Appendix - 3 .

${ }^{14} \mathrm{As}$ a robustness check, we have also examined the model with government debt which is issued to the capitalists. In the optimal policy setup, we allow the Ramsey government to optimally choose the debt level. The optimal taxation results are close to those in the model without debt. This is consistent with Arsenau and Chugh (2012) who study optimal tax smoothing in a model with search friction in the labour market. They show that optimal policy results in the model have nothing to do with completeness or incompleteness of government debt markets.
} 
where $\delta^{g}$ is the constant depreciation rate of public capital stock. The public capital and private capital are assumed to depreciate at the same rate, so that $\delta^{g}=0.1 .^{15}$

Government expenditures include government consumption which is utilityenhancing, unemployment benefits, and public investment. They are financed by the tax revenues from capitalists and workers.

Both sides of the constraint (18) are divided by the total population, $N$, and we make use of the population relationships, $N^{k} / N=n^{k}, N^{w} / N=1-n^{k}$ and $N^{f}=N^{k}$, to get the per capita government budget constraint as follows:

$$
\begin{aligned}
& \bar{G}_{t}^{c}+\left(1-n^{k}\right) \bar{r}_{t} w_{t}\left(1-H_{t}^{w}\right)+n^{k} \bar{I}_{t}^{g} \\
= & n^{k}\left(\tau_{t}^{k}\left(r_{t}-\delta^{p}\right) K_{t}^{k}+\tau_{t}^{k} \pi_{t}^{k}\right)+\left(1-n^{k}\right) \tau_{t}^{w} w_{t} H_{t}^{w} .
\end{aligned}
$$

\subsection{Market clearing conditions and resource constraint}

In the capital market, the aggregate supply of capital is equal to the aggregate demand of capital. This implies:

$$
N^{k} K_{t}^{k}=N^{f} K_{t}^{f}
$$

It has been assumed that $N^{k}=N^{f}$, so that the above condition implies:

$$
K_{t}^{k}=K_{t}^{f} .
$$

In the labour market, the aggregate supply of labour is equal to the aggregate demand of labour:

$$
N^{w} H_{t}^{w}=N^{k} H_{t}^{f} .
$$

The per capita market clearing condition for the labour is:

$$
H_{t}^{w}=\frac{n^{k}}{\left(1-n^{k}\right)} H_{t}^{f}
$$

The profits are equally redistributed to the capitalists, so that:

$$
\pi_{t}^{k}=\pi_{t}^{f}
$$

\footnotetext{
${ }^{15}$ Because in what follows, the focus will only be on the steady-state analysis of the model, the ratio of aggregate public investment to aggregate output, $g^{i}$, is set to the data average. In the Ramsey setup, the government optimally chooses $\bar{K}_{t+1}^{g}$, and $\bar{I}_{t}^{g}$ is substituted out using the public capital evolution equation, (19).
} 
Finally, in the goods market, the economy's aggregate resource constraint is given by:

$$
\begin{aligned}
& N^{f} A\left(K_{t}^{f}\right)^{\alpha_{1}}\left(H_{t}^{f}\right)^{\alpha_{2}}\left(\bar{K}_{t}^{g}\right)^{\alpha_{3}} \\
= & N^{k} C_{t}^{k}+N^{w} C_{t}^{w}+N^{k}\left(K_{t+1}^{k}-\left(1-\delta^{p}\right) K_{t}^{k}\right)+N \bar{G}_{t}^{c}
\end{aligned}
$$

which can be re-written in per capita terms:

$$
\begin{aligned}
& n^{k} A\left(K_{t}^{f}\right)^{\alpha_{1}}\left(H_{t}^{f}\right)^{\alpha_{2}}\left(\bar{K}_{t}^{g}\right)^{\alpha_{3}} \\
= & n^{k} C_{t}^{k}+\left(1-n^{k}\right) C_{t}^{w}+n^{k}\left(K_{t+1}^{k}-\left(1-\delta^{p}\right) K_{t}^{k}\right)+\bar{G}_{t}^{c} .
\end{aligned}
$$

\subsection{Decentralized competitive equilibrium (exogenous policy)}

We now summarise the decentralized competitive equilibrium (DCE) conditions in the model. Given the three tax policy instruments $\left\{\tau_{t}^{k}, \tau_{t}^{w}, \bar{r}_{t}\right\}_{t=0}^{\infty}$ and the initial conditions for $K_{0}^{k}$ and $\bar{K}_{0}^{g}$, the DCE is defined to be a sequence of allocations $\left\{C_{t}^{k}, K_{t+1}^{k}, C_{t}^{w}, H_{t}^{w}, K_{t}^{f}, H_{t}^{f}, \bar{K}_{t+1}^{g}\right\}_{t=0}^{\infty}$, prices $\left\{r_{t}, w_{t}\right\}_{t=0}^{\infty}$, and one residually determined policy instrument $\left\{\bar{G}_{t}^{c}\right\}_{t=0}^{\infty}$, such that (i) capitalists, workers and firms undertake their respective optimisation problems; (ii) all budget constraints are satisfied; and (iii) all markets clear.

Thus the DCE consists of the capitalist's and worker's optimality conditions, i.e. $O C^{k}$ and $O C^{w}$; the firm's first-order conditions for $K_{t}^{f}$ and $L_{t}^{f}$, $F O^{k}$ and $F O^{l}$; the budget constraints of capitalist, worker and government, i.e. $B C^{k}, B C^{w}$ and $B C^{g}$; the public capital evolution equation, $P C^{g}$, and the per capita market clearing conditions in capital and labour markets, i.e. $M C^{k}$ and $M C^{l}{ }^{16}$

\subsection{Calibration and steady-state (exogenous policy)}

The structural parameters of the model are calibrated using the annual data of the UK economy over the period 1970-2009. All the data is obtained from International Monetary Fund (IMF), United Nation Statistics Division (UNSD), the Office for National Statistics (ONS), OECD International Sectorial Data Base (ISDB) and OECD Economic Outlook. The IMF data is

\footnotetext{
${ }^{16}$ The full DCE conditions are provided in the Appendix - 4. Relying on the Walras's law, if the budget constraints of capitalists and workers and the government budget constraint are satisfied, then the resource constraint is redundant and it can be dropped from the equilibrium.
} 
from the World Economic Outlook (WEO) database. The UNSD databases include: (i) World Bank (WB) database; (ii) National Accounts Statistics (NAS) database; and (iii) International Financial Statistics (IFS) database. The ONS data is from Labour Force Survey (LFS) database. The OECD data is from OECD tax database.

The structural parameters of the model are assigned values so that the model's steady-state solution can reflect the main empirical characteristics of the UK economy with particular focus on its unemployment rate. The calibrated values for the structural parameters are reported in Table 1 as follows.

\section{[Table 1 about here]}

The labour's share of output, $\alpha_{2}=0.6$, is obtained directly from the ISDB dataset. The public capital's share of output, $\alpha_{3}$ is 0.025 giving the profits of $2.5 \%$ out of GDP which is in line with the data. The private capital's share of output is therefore: $\alpha_{1}=1-\alpha_{2}-\alpha_{3}=0.025$. The annual rate of time preference, $\beta$, is 0.97 . The annual depreciation rate of capital stock is $10 \%$, which is consistent with $2.5 \%$ quarterly depreciation rate of capital stock. The degree of substitutability across private and public consumption, $\omega$, is set to 0.4. This is in line with Ahmed (1986, see Tables 1 and 2) who estimated this parameter for the UK economy. The elasticity of substitution between consumption and leisure, $\sigma$, is set to 2 which is common in the DGE literature. The constant TFP is normalised to 1 . The steady-state values of exogenous policy instruments, $\left\{\tau^{k}, \tau^{w}, \bar{r}, g^{i}\right\}$, are set to their respective data averages. All the tax data are obtained from OECD tax database. ${ }^{17}$

The capitalists do not work in the model economy, but they can save in the form of private capital stock, own firms and receive dividends of firms. Following Ardagna (2007), the self-employed are treated as capitalists in the economy in order to calibrate the population share of capitalists, $n^{k}$. The data of self-employment only became available from 1992 for the UK economy in the LFS database. The data average is 0.115 , so that $n^{k}=0.115$. Finally, the value for $\mu$ is calibrated in order to get the steady-state unemployment rate of $7 \%$ which coincides with the data average between 1970 and 2009 .

In the long run, the economy converges to a steady state when all the variables remain constant. Table 2 below shows the steady-state ratios of aggregate capital stock, investment and consumption to output, and the steady-state employment generated by the model given the above parame-

\footnotetext{
${ }^{17}$ The average marginal tax rates on capital and labour income in the data are used for $\tau^{k}$ and $\tau^{w}$. The replacement rate, $\bar{r}$, is a net rate after the deduction of taxes. The value for $\bar{r}$ is similar to Ardagna (2007).
} 
terisation. ${ }^{18}$ The same table also gives their data averages.

[Table 2 about here]

As can be seen from Table 2, the model's steady solution matches most of the data averages well.

\section{Optimal policy with commitment}

\subsection{Ramsey problem}

In the commitment framework, the government takes into account that the households and firms will behave in their own best interest by taking all the fiscal policy variables as given. Each applicable fiscal policy implies a feasible equilibrium allocation that fully reflects the optimal behavioral responses of resources. Given a welfare criterion, the optimization problem for the government is to pick the best fiscal policy which can produce an equilibrium allocation giving the highest aggregate welfare. To avoid the general time inconsistency problem in policy making, the government is assumed to commit itself once-and-for-all to one fiscal policy which is announced at initial period and never re-optimises. ${ }^{19}$ This problem is usually referred to as the Ramsey problem of government under commitment.

The government now optimally chooses some of its policy instruments. Meanwhile, it also chooses the allocation of private agents. This is called the dual approach to the Ramsey problem. ${ }^{20}$ The objective of government is to maximize the present discounted value of a weighted average of capitalists' and workers' welfare:

$$
\sum_{t=0}^{\infty} \beta^{t}\left[\gamma U_{t}^{k}+(1-\gamma) U_{t}^{w}\right]
$$

where the government is assumed to have the same discount rate as households; and $0<\gamma,(1-\gamma)<1$ are the weights on the welfare of capitalists and workers.

\footnotetext{
${ }^{18}$ In Table 2, $C$ is defined as the aggregate consumption of capitalists and workers at steady-state, i.e. $C=n^{k} C^{k}+\left(1-n^{k}\right) C^{w}$.

${ }^{19}$ The time inconsistency refers to that when the government revises its policy annouced initially if it has a chance to do so.

${ }^{20}$ In contrast to the dual approach, the government only chooses the allocation of private agents and all the policy variables are substituted out using DCE conditions in the primal approach.
} 
The optimal policy approach emphasizes the constraints under which the government must operate. These constraints include the requirement to raise enough tax revenues and the behavioral responses of households and firms. These are summarized in the DCE conditions. In order to simplify the optimization problem of the government - it is necessary to reduce the number of choice variables for the government, we substitute out, $r_{t}, w_{t}, K_{t}^{f}$, and $L_{t}^{f}$, by making use of DCE conditions, $F O^{k}, F O^{l}, M C^{k}$ and $M C^{l}$. The per capita government consumption, $\bar{G}_{t}^{c}$, is assumed to be constant in the Ramsey problem, i.e. $\bar{G}_{t}^{c} \equiv \bar{G}^{c}$ for all time periods. To summarise, in the dual approach of the Ramsey problem, the choice variables for the government are five allocation variables, $\left\{C_{t}^{k}, H_{t}^{w}, C_{t}^{w}, K_{t+1}^{k}, \bar{K}_{t+1}^{g}\right\}_{t=0}^{\infty}$ and three policy variables $\left\{\tau_{t}^{k}, \tau_{t}^{w}, \bar{r}_{t}\right\}_{t=0}^{\infty}$. The initial conditions for $K_{0}^{k}$ and $\bar{K}_{0}^{g}$ are taken as given. The optimisation problem can thus be summarised as follows:

$$
\max _{\left\{C_{t}^{k}, H_{t}^{w}, C_{t}^{w}, K_{t+1}^{k}, \bar{K}_{t+1}^{g}, \tau_{t}^{k}, \tau_{t}^{w}, \bar{r}_{t}\right\}_{t=0}^{\infty}} E_{0} \sum_{t=0}^{\infty} \beta^{t}\left[\gamma U\left(C_{t}^{k}\right)+(1-\gamma) U\left(C_{t}^{w}\right)\right]
$$

subject to the DCE conditions of

$$
\begin{aligned}
&\left(C_{t}^{k}+\omega \bar{G}^{c}\right)^{-\frac{1}{\sigma}}\left[\mu\left(C_{t}^{k}+\omega \bar{G}^{c}\right)^{\frac{\sigma-1}{\sigma}}+(1-\mu)\right]^{\frac{1}{\sigma-1}} \\
&=\beta E_{t}\left\{\left(C_{t+1}^{k}+\omega \bar{G}^{c}\right)^{-\frac{1}{\sigma}}\left[\mu\left(C_{t+1}^{k}+\omega \bar{G}^{c}\right)^{\frac{\sigma-1}{\sigma}}+(1-\mu)\right]^{\frac{1}{\sigma-1}}\right. \\
&\left.\cdot\left[1+\left(1-\tau_{t+1}^{k}\right)\left(r_{t+1}-\delta^{p}\right)\right]\right\} \\
& \quad(1-\mu)\left(1-H_{t}^{w}\right)^{-\frac{1}{\sigma}}+\mu \bar{r}_{t} w_{t}\left(C_{t}^{w}+\omega \bar{G}^{c}\right)^{-\frac{1}{\sigma}} \\
&=\mu w_{t}\left(1-\tau_{t}^{w}\right)\left(C_{t}^{w}+\omega \bar{G}^{c}\right)^{-\frac{1}{\sigma}} \\
& C_{t}^{k}+K_{t+1}^{k}-\left(1-\delta^{p}\right) K_{t}^{k}=r_{t} K_{t}^{k}-\tau_{t}^{k}\left(r_{t}-\delta^{p}\right) K_{t}^{k} \\
& C_{t}^{w}=\left(1-\tau_{t}^{w}\right) w_{t} H_{t}^{w}+\bar{r}_{t} w_{t}\left(1-H_{t}^{w}\right) \\
& \bar{G}^{c}+\left(1-n^{k}\right) \bar{r}_{t} w_{t}\left(1-H_{t}^{w}\right)+n^{k}\left(\bar{K}_{t+1}^{g}-\left(1-\delta^{g}\right) \bar{K}_{t}^{g}\right) \\
&=n^{k}\left(\tau_{t}^{k}\left(r_{t}-\delta^{p}\right) K_{t}^{k}+\tau_{t}^{k} \pi_{t}^{k}\right)+\left(1-n^{k}\right) \tau_{t}^{w} w_{t} H_{t}^{w}
\end{aligned}
$$


The Lagrangian function of the government can be written as:

$$
\begin{aligned}
L^{g}= & E_{0} \sum_{t=0}^{\infty} \beta^{t}\left\{\gamma\left[\mu\left(C_{t}^{k}+\omega \bar{G}^{c}\right)^{\frac{\sigma-1}{\sigma}}+(1-\mu)(1-0)^{\frac{\sigma-1}{\sigma}}\right]^{\frac{\sigma}{\sigma-1}}+\right. \\
& +(1-\gamma)\left[\mu\left(C_{t}^{w}+\omega \bar{G}^{c}\right)^{\frac{\sigma-1}{\sigma}}+(1-\mu)\left(1-H_{t}^{w}\right)^{\frac{\sigma-1}{\sigma}}\right]^{\frac{\sigma}{\sigma-1}}+ \\
& +\lambda_{t}^{1}\left[\beta\left(C_{t+1}^{k}+\omega \bar{G}^{c}\right)^{-\frac{1}{\sigma}}\left[\mu\left(C_{t+1}^{k}+\omega \bar{G}^{c}\right)^{\frac{\sigma-1}{\sigma}}+(1-\mu)\right]^{\frac{1}{\sigma-1}}\right. \\
& +\left[1+\left(1-\tau_{t+1}^{k}\right)\left(r_{t+1}-\delta^{p}\right)\right]- \\
& \left.-\left(C_{t}^{k}+\omega \bar{G}^{c}\right)^{-\frac{1}{\sigma}}\left[\mu\left(C_{t}^{k}+\omega \bar{G}^{c}\right)^{\frac{\sigma-1}{\sigma}}+(1-\mu)\right]^{\frac{1}{\sigma-1}}\right]+ \\
& +\lambda_{t}^{2}\left[\mu w_{t}\left(1-\tau_{t}^{w}\right)\left(C_{t}^{w}+\omega \bar{G}^{c}\right)^{-\frac{1}{\sigma}}-\right. \\
& \left.-(1-\mu)\left(1-H_{t}^{w}\right)^{-\frac{1}{\sigma}}-\mu \bar{r}_{t} w_{t}\left(C_{t}^{w}+\omega \bar{G}^{c}\right)^{-\frac{1}{\sigma}}\right]+ \\
& +\lambda_{t}^{3}\left[r_{t} K_{t}^{k}-\tau_{t}^{k}\left(r_{t}-\delta^{p}\right) K_{t}^{k}-C_{t}^{k}-K_{t+1}^{k}+\left(1-\delta^{p}\right) K_{t}^{k}\right]+ \\
& +\lambda_{t}^{4}\left[\left(1-\tau_{t}^{w}\right) w_{t} H_{t}^{w}+\bar{r}_{t} w_{t}\left(1-H_{t}^{w}\right)-C_{t}^{w}\right]+ \\
& +\lambda_{t}^{5}\left[n^{k}\left(\tau_{t}^{k}\left(r_{t}-\delta^{p}\right) K_{t}^{k}+\tau_{t}^{k} \pi_{t}^{k}\right)+\left(1-n^{k}\right) \tau_{t}^{w} w_{t} H_{t}^{w}-\right. \\
& \left.\left.-\bar{G}^{c}-\left(1-n^{k}\right) \bar{r}_{t} w_{t}\left(1-H_{t}^{w}\right)-n^{k}\left(\bar{K}_{t+1}^{g}-\left(1-\delta^{g}\right) \bar{K}_{t}^{g}\right)\right]\right\}
\end{aligned}
$$

where $\lambda_{t}^{i}, i=1,2, \cdots, 5$, represents the multiplier associated with each constraint in $(D 1)-(D 5)$. The constraints in the Lagrangian function have been rearranged so that all the multipliers are non-negative at the steady-state.

Some FOCs of the government at time 0 are different from the same rules governing behavior from time 1 on. Specifically, these include the FOCs of $C_{t}^{k}, H_{t}^{w}$ and $\tau_{t}^{k}$ and these variables appear in the forward-looking intertemporal optimality condition $(D 1)$ and $(D 5)$. To avoid this problem, it is necessary to consider the Ramsey problem in the economy starting from time 1 and assume that time 0 optimality conditions of the government do not alter the results in equilibrium.

In addition, the FOCs of the government should also include the constraints to the Ramsey problem, i.e. $(D 1)-(D 5) .^{21}$

\subsection{Benthamite (non-partisan) optimal taxation}

We now use the above parameterisation to calculate the steady-state of Ramsey policy. We first study the Benthamite government. This implies that the

\footnotetext{
${ }^{21}$ We do not show the FOCs of government in the Ramsey problem to preserve space. But they are available upon request.
} 
weights on the welfare of capitalists and workers in the objective function of government are equal to their respective population shares, i.e. $\gamma=n^{k}$ and $1-\gamma=1-n^{k}$. Using the parameters in Table 1, we can get the steadystate solutions of optimal policy in models with profits and without profits in Table $3 .^{22}$ They are compared to their respective steady-state solution with exogenous policy. ${ }^{23}$

\section{[Table 3 about here]}

Table 3 incorporates the following findings. First, in the absence of profits, the celebrated result of Judd (1985) and Chamley (1986) is verified: the optimal capital tax is zero in the long run. This implies that capitalists are exempted from paying taxes in the long run. All the government expenditures should be financed by the taxes on workers. ${ }^{24}$ This result is silent about the transition to the steady-state. If $\tau^{k}$ is positive, it reduces the return from today's savings and therefore makes the consumption of next period more expensive relative to current period. In the model with infinitely-lived households, the long-run positive tax rate on capital income implies that the implicit tax rate on consumption of future periods increases without bound. However, the relevant elasticity of demand for consumption in all periods is constant. Therefore taxing consumption at different rates violates the general public finance principle stating that tax rates should be inversely proportional to the demand elasticities of consumption. The assumption of constant demand elasticity of consumption implies that the capital income tax rate should be zero in the long run. As a result, zero capital income tax stimulates the investment of capitalists (i.e. from 3.79 to 4.833 ), and this is transformed into higher capital stock (i.e. from 37.895 to 48.332 ).

In the model with public investment and therefore economic profits, the result of long-run optimal zero capital tax rate cannot be obtained. This result is consistent with Lansing (1999). He argues that the existence of profits, together with the assumption that the government cannot distinguish between profits and other asset incomes can result in a non-zero optimal capital income tax in the long run. The steady-state optimal tax rate on

\footnotetext{
${ }^{22}$ For the model without public investment, we use the parameters in Table 1, except for $\mu$, which is recalibrated to get $H^{w}=0.93$. As a result, the steady-state solution looks slightly different.

${ }^{23}$ In Table $3, U$ is defined as the aggregate welfare of capitalists and workers at steadystate, i.e. $U=n^{k} U^{k}+\left(1-n^{k}\right) U^{w}$.

${ }^{24}$ In the model with non-zero economic profits, this result does not hold any more. The two opposing effects on the sign of optimal tax rate on capital income will be demonstrated later.
} 
capital income is negative. ${ }^{25}$ This implies that it is optimal for the government to subsidise the interest income from capital and profits in the long run and it is accomplished by increasing the labour income tax. Guo and Lansing (1999) show that in an imperfectly competitive economy, the sign of the steady-state optimal capital income tax is ambiguous and find that this ambiguity mainly results from two opposite effects: under-investment effect and profit effect. The under-investment effect arises when the private agent under-invests relative to the socially optimal level as the interest rate that determines the equilibrium investment is smaller than the social marginal product of capital. Therefore, a negative tax rate on capital income helps to correct the existence of under-investment in the capital market. The profit effect, in contrast, motivates the use of a positive tax rate on capital income, because taxing profits does not affect private agent's decisions at the margin such that it does not distort incentives of investment. In this case, the government has an incentive to fully confiscate the profits. This motivates a positive tax rate on capital income. In the model with the presence of public investment, the crowding-out of the public investment is equivalent to the under-investment effect and it dominates the profit effect. As a result, the steady-state optimal tax rate on capital income turns out to be negative. The negative capital tax increases the private investment of capitalists (i.e. from 3.089 to 4.047 ). This is transformed into higher private capital (i.e. from 30.892 to 40.472$).^{26}$

Second, the optimal replacement rate turns out to be negative in the long run in both cases. It predicts that the government taxes unemployed workers rather than offer unemployment benefits. The difference between the level of potential labour supply and the level of labour supply chosen by the workers is treated as unemployment. From the workers' point of view, some may choose to stay unemployed as the combination of receiving unemployment benefits and enjoying leisure is more favorable to them. A negative replacement rate implies that the government taxes those workers who do not work up to their full available labour. Under this optimal policy, leisure generates income losses for those workers. Alternatively, we can understand the

\footnotetext{
${ }^{25}$ Judd (1997) shows that the tax rate on capital income is ambiguous if the government does not distinguish between taxing returns on new investment and taxing economic profits. His paper, however, mainly studies on the sub-optimality of a capital income tax. Judd (1999) argues that a tax on capital cannot be optimal as its distortions accumulate over time, a pattern that is inconsistent with the commodity tax principle. Later, Judd (2002) proposes an optimal capital income subsidy referring to the repealed Investment Tax Credit scheme in the US economy.

${ }^{26}$ In the version of the model where profits are generated by monopolistic competition as in Guo and Lansing (1999), the results are qualitatively similar although quantitatively larger.
} 
negative replacement rate as a subsidy to the workers at work. ${ }^{27}$ Therefore, the negative, $\bar{r}$, leads to an increase in the labour supply of workers. The optimal tax rate on labour income, $\tau^{w}$, increases relative to the exogenous policy case. This, in contrast, has a negative effect on the labour supply. Overall, the labour supply increases resulting from the dominant positive effect of negative replacement rate.

Third, the labour wedge defined by $1-\tau^{w}-\bar{r}$ is equal to one at the steady state in the model without profits. This implies that the marginal product of labour is equal to the marginal rate of substitution between leisure and consumption. In the words, in absence of profits, the labour wedge can be completely eliminated by the government in the long run. This happens because, in Ramsey, the government optimally chooses two tax rates on workers, i.e. $\tau_{t}^{w}$ and $\bar{r}_{t}$. At the steady state, the wedge between the marginal product of labour and the marginal rate of substitution between leisure and consumption created by $\tau^{w}$ is exactly canceled out by the negative $\bar{r}$. As a result, there is no distortion in the labour market. This result also explains the large increase in labour supply which is consistent with the finding in Prescott (2002 and 2004). The welfare of all agents improves and the Ramsey solution is Pareto improving in the long run. The labour wedge is no longer equal to one at the steady-state in the model with non-zero profits. This implies that there exists a discrepancy between the marginal rate of substitution between leisure and consumption and the marginal product of labour. The labour market distortion exists in the modified model. The Benthamite optimal taxation, with the presence of profits, generates conflict of interests between agents. It leads to distributional effects in the long run. This is because the under-investment distortion is so large in the capital market that it increases the incentive for the government to impose a subsidy to capital income. In turn, this reduces the incentive for the government to eliminate the distortion in the labour market. Because of labour market distortion, the welfare of workers decreases in the Ramsey setup (i.e. from 0.680 to 0.676 ). The welfare of capitalists increases (i.e. from 1.191 to 1.592) as the subsidy to capital income together with the profits increases the income and consumption of capitalists. The optimal policy increases the aggregate welfare (from 0.739 to 0.782 ) despite welfare losses for the workers in the long run.

Finally, the output, $Y^{f}$, increases substantially at the steady-state in both cases as a result of the increase in all inputs. This generates positive welfare

\footnotetext{
${ }^{27}$ The budget constraint of workers (10) at the steady state can be rewritten as: $C^{w}=$ $\left(1-\tau^{w}-\bar{r}\right) w H^{w}+\bar{G}^{u}$. A negative replacement rate therefore implies that the government subsidizes the labour supply of workers. The last term, $\bar{G}^{u}=\bar{r} w<0$, can be considered as a lump-sum tax paid by the workers at the steady-state which does not generate any distortion in the economy.
} 
effects on private consumption and investment as can be seen in aggregate resource constraint.

\subsection{Non-Benthamite (partisan) optimal taxation}

The next case to be investigated is that of a partisan government. In other words, the weights on the welfare of each agent in Ramsey problem are not equal to the population share of each agent so that the government is biased. Tables 4 and 5 report the steady-state solutions of the optimal policy under different values of $\gamma$ for models without profits and with profits, respectively. The case of Benthamite government is highlighted in bold.

\section{[Tables 4 and 5 about here]}

As in Judd (1985), we find that the optimal taxation and allocation under commitment are independent of weights attached to the welfare of agents in the model with no profits. This implies that, for all agents, the zero capital tax and elimination of labour wedge are the best option to adopt in the Ramsey set-up of government. This holds even if the government cares only about the workers, so that there is no conflict of interests between agents.

In contrast, the value of $\gamma$ matters for the steady-state solution in the model with non-zero profits. In addition, Figure 1 below plots the steadystate values for the policy instruments, equilibrium allocations and welfare of different agents against the weight on the welfare of capitalists, $\gamma$. As can be seen from the table and figure, the changes of variables are monotonic with the magnitude of $\gamma$.

[Figure 1 about here]

When the government cares only about the workers, the capital income rate is positive and well below the date average of $34.4 \%$. The incentive for the government to tax labour income is reduced. The labour income tax is below the data average of $18.8 \%$. In this case, the replacement rate is negative which implies the government subsidises the labour supply in the long run. When $\gamma=0$, the welfare of workers improves at the steadystate of Ramsey relative to the exogenous policy case. (i.e. from 0.68 to 0.689). As weight for the welfare of capitalists increases, the capital income tax falls very quickly, as can be seen in Figure 1. The steady-state optimal capital tax turns into a subsidy when $\gamma$ reaches 0.110 , i.e. $\tau^{k}=-0.053$. In turn, the labour income tax increases to make up for the tax revenue losses from capital. This optimal policy hurts the workers and the welfare of workers decreases relative to the exogenous policy case (i.e. from 0.680 to 0.679). This implies that the government redistributes the welfare towards 
capitalists if $\gamma$ exceeds 0.110 . The replacement rate decreases as $\gamma$ increases. This implies the government increases the subsidy to labour as $\gamma$ increases. This policy increases the incentive for the workers to provide labour to firms. As a result, employment goes up (i.e. from 0.974 to 0.978 ).

When the weight on the welfare of capitalists increases, the steady-state welfare of capitalists increases. It is because the capitalists directly benefit from the substantial reductions in capital tax. In contrast, the increase in $\gamma$ worsens the welfare of workers. However, the workers are slightly hurt by the labour tax increases since the subsidy to labour increases in the meanwhile. The output, $Y^{f}$, goes up as a result of increases in three inputs, $K^{k}, H^{w}$ and $\bar{K}^{g}$. Moreover, the aggregate welfare improves as $\gamma$ increases. This implies that the efficiency of the whole economy has improved as the government becomes biased towards the capitalists.

The above discussion suggests that, in the model with strictly positive profits, when the government cares more about the capitalists, it helps to reduce the inefficiently high capital tax and eventually it turns into a subsidy after a critical level of the weight on the welfare of capitalists placed by the government. The welfare of capitalists substantially improves as the capital distortion reduces. Meanwhile, the optimal policy hurts the workers as the government has to raise the revenue to the required level by increasing labour income tax. As a result, the welfare of workers worsens. This implies a conflict of interests between the agents and hence a trade-off between efficiency and equity. This result is consistent with Angelopoulos et al. (2011).

\subsection{Welfare analysis}

This section examines the welfare effects of optimal taxation at the steadystate in order to investigate the distributional effects of optimal taxation. In particular, the steady-state welfare costs or benefits for all agents are computed when the government chooses the optimal policy relative to the exogenous policy. This has become one popular way to evaluate fiscal policies in recent literature (see e.g. Baier and Glomm (2001) and Ardagna (2007)). Following Lucas (1990), Cooley and Hansen (1992) and Ohanian (1997), the additional level of consumption, $\zeta^{i}$ to give to the agent is calculated so that he is equally well off in two cases of exogenous policy and optimal policy. Mathematically, $\zeta^{i}$ satisfies the following equation:

$$
U_{R}^{i}=\bar{U}_{E}^{i}=\left[\mu\left(C_{E}^{i}\left(1+\zeta^{i}\right)+\omega \bar{G}_{E}^{c}\right)^{\frac{\sigma-1}{\sigma}}+(1-\mu)\left(1-H_{E}^{i}\right)^{\frac{\sigma-1}{\sigma}}\right]^{\frac{\sigma}{\sigma-1}} .
$$

The welfare losses and gains for the capitalists and the workers are denoted by $\zeta^{k}$ and $\zeta^{w}$, respectively, together with the welfare losses and gains 
at the aggregate level, $\zeta .{ }^{28}$ The subscript $E$ denotes the exogenous policy while the subscript $R$ denotes the Ramsey policy $\bar{U}_{E}^{i}$ is the contingent utility of agent $i$ in the model with exogenous policy in which he would increase $\zeta^{i}$ fraction of the consumption such that he can enjoy the same utility as in the model with optimal policy.

A positive $\zeta^{i}$ implies that the agent is better off in the optimal policy case while a negative $\zeta^{i}$ implies that the agent is better off in the exogenous policy case. The agent will be indifferent about two policies if $\zeta^{i}$ is zero.

[Table 6 about here]

As can be seen in Table 6, the optimal taxation in Ramsey can improve the welfare of all agents in all cases of different $\gamma$, in the model with zero profits. There does not exist a conflict of interests between agents. The long-run optimal zero capital taxation holds no matter the weight attached to the welfare capitalists, i.e. $\zeta^{k}=0.276>0$. This is because the long-run optimal zero capital tax increases the private investment and therefore capital stock. The income and consumption of capitalists increases in the long run. Recalling the utility function of capitalists, the welfare of capitalists depends on the private consumption and per capita government consumption because the capitalists do not work in the economy. The increase in private consumption increases the welfare of capitalists. The welfare of workers improves as well. It has been demonstrated, in the steady-state analysis above, that the long-run optimal negative replacement rate is equivalent to a subsidy to work. This leads to a rise in the labour supply of workers. On one hand, the income, consumption welfare of workers increases as a result of higher labour supply as working can generate higher income for the workers. On the other hand, the welfare of workers decreases because the utility of workers negatively depends on the labour supply. The positive effect dominates and the workers are better off in the setup of Ramsey, i.e. $\zeta^{w}=0.028>0$. Both capitalists and workers are better off at the steady-state of Ramsey setup no matter whether the government is Benthamite or partisan. The optimal policy is Pareto improving in the long run, but the welfare gains for the capitalists relative to the workers are bigger. This implies that the optimal taxation increases the welfare inequality.

Apparently, the commonality of interests no longer holds in the modified model with strictly positive profits. The presence of profits creates the conflict of interests between agents. When the government cares more about the capitalists, it substantially decreases the capital income tax in order to reduce the distortion in the capital market. The capital income tax

\footnotetext{
${ }^{28}$ The derivation of the formula for $\zeta^{i}$ is provided in Appendix - 5 .
} 
turns into a subsidy when $\gamma$ exceeds 0.110 . The capital tax cut is associated with a higher labour income tax. Thus, the welfare of workers goes down as $\gamma$ increases. When the weight attached to the welfare of capitalists increases above the critical value of 0.110 , the steady-state welfare of workers decreases in the optimal policy case compared to the exogenous policy case, i.e. $\zeta^{w}=-0.003<0$.

The above findings show that, with the presence of profits, the government redistributes welfare towards capitalists, when $\gamma$ reaches a critical level. In the modified model with non-zero profits, the government values distortion in the capital market more than labour market distortion. This incentive leads to a decrease in the optimal capital income tax and therefore the longrun welfare gains for capitalists increase while the welfare gains for workers decrease as $\gamma$ increases. Therefore, there is a conflict of interests between agents.

\section{Summary and conclusions}

This paper uses a heterogeneous agent model to study the effects of optimal taxation on unemployment, the distribution of income, and welfare of agents. Agent heterogeneity is introduced through the working and saving propensities of households. By assumption, capitalists do not work and workers do not save. Equilibrium unemployment is generated in the competitive labour market as the outcome of optimal choices made by workers. The government can invest in production which results in economic profits. The main findings can be summarised as follows.

First, in the model with zero economic profits, we show that the optimal tax rate on capital income should be zero in the long run which is consistent with Judd (1985) and Chamley (1986). It is optimal for the government to tax the leisure of workers in the long run. This is equivalent to a subsidy to the labour supply of workers. Meanwhile, the government slightly increases the tax rate on labour income. The distortions in the labour market caused by the distortionary labour tax can be completely eliminated as a consequence of the equal amount of government subsidies to the workers in the form of taxation on the leisure. As a result, the labour supply of workers increases which is beneficial to workers. The income, consumption, and welfare of workers improves in the long run. In addition, as in Judd (1985), The weight on the welfare of agent in the Ramsey setup of the government does not matter for the long-run optimal policy. This implies that there is no conflict of interests between agents in the long run.

Second, the result of long-run optimal zero capital tax cannot be obtained 
in the modified model. The optimal tax rate on capital income is found to be negative in the long run which means the government chooses to subsidise capital income in the long run. There are two opposing effects in determining the direction of optimal capital taxation: the under-investment effect and the profit effect (see e.g. Guo and Lansing (1999)). In our model, on the one hand, the crowding-out effect of public investment is equivalent to the underinvestment effect which motivates a Benthamite government to use a subsidy to the capital income to help reduce the distortions in the capital market. On the other hand, the presence of profits motivates the government to use a positive tax rate on capital income as taxing profits is not distortionary. In our case, we show that the under-investment effect outweighs the profit effect. As a result, the government subsidises capital income in the long run. The negative capital income tax directly increases the investment of capitalists and therefore the income, consumption and welfare of capitalists increase. As in the model with no profits, the government subsidises the labour supply of workers while the tax rate on labour income slightly increases. These two policy instruments have opposing effects on the labour supply of workers. We find that the positive effect of labour subsidy dominates so that the labour supply of workers is higher than it would be in the model with given policy. In the presence of profits, the tax distortion in the labour market cannot be completely eliminated in the long run. The distortion causes welfare losses for workers. Finally, in contrast to the model with no profits, the weight to the welfare on agent matters for the optimal taxation under commitment in the modified model. The effects are found to be monotonic. This implies that the optimal taxation generates conflict of interests between agents and it has redistributional effects in the long run. As the weight on the welfare of capitalists increases, capital taxation decreases and it turns into a subsidy after a critical value. The tax rate on labour income increases in order to make up for the losses in government's tax revenues. In this case, a trade-off between efficiency and equity needs to be taken into account in the Ramsey setup of government. 


\section{References}

[1] Ahmed, S. (1986). 'Temporary and permanent government spending in an open economy: some evidence for the UK', Journal of Monetary Economics, vol. 17, pp. 197-224.

[2] Ai, C. and Cassou, S. (1995). 'A normative analysis of public capital', Applied Economics, vol. 27, pp. 1201-1209.

[3] Ambler, S. and Paquet, A. (1996). 'Fiscal spending shocks, endogenous government spending, and real business cycles', Journal of Economic Dynamics and Control, vol. 20, pp. 237-256.

[4] Angelopoulos, K., Asimakopoulos, S. and Malley, J. (2017). ' The optimal distribution of the tax burden over the business cycle', Macroeconomic Dynamics, forthcoming.

[5] Angelopoulos, K., Malley, J. and Philippopoulos, A. (2011). 'Timeconsistent fiscal policy under heterogeneity: Conflicting or common interests?', CESifo Working Paper Series: 3444, CESifo Group Munich.

[6] Ardagna, S. (2001). 'Fiscal policy composition, public debt, and economic activity', Public Choice, vol. 109, pp. 301-325.

[7] Ardagna, S. (2007). 'Fiscal policy in unionized labor markets', Journal of Economic Dynamics and Control, vol. 31, pp. 1498-1534.

[8] Arsenau, D. and Chugh, S. (2012). 'Tax smoothing in frictional labor markets', Journal of Political Economy, vol. 120, 926-985.

[9] Aschauer, A. (1985). 'Fiscal policy and aggregate demand', American Economic Review, vol. 75, pp. 117-127.

[10] Aschauer, A. (1989). 'Is public expenditure productive?', Journal of Monetary Economics, vol. 23, pp. 177-200.

[11] Aschauer, A. and Greenwood, J. (1985). 'Macroeconomic effects of fiscal policy', Carnegie-Rochester Conference Series on Public Policy, vol. 23, pp. 91-138.

[12] Asimakopoulos, S. and Asimakopoulos, P. (2017). 'Fiscal policy with banks and financial frictions', Journal of Financial Stability, forthcoming. 
[13] Baier, S. and Glomm, G. (2001). 'Long-run growth and welfare effects of public policies with distortionary taxation', Journal of Economic Dynamics and Control, vol. 25, pp. 2007-2042.

[14] Barro, J. (1981). 'Output effects of government purchases', Journal of Political Economy, vol. 89, pp. 1086-1121.

[15] Barro, J. (1989). 'The neoclassical approach to fiscal policy', Modern Business Cycle Theory, Harvard University Press, Cambridge, Massachusetts, pp. 178-235.

[16] Burnside, C., Eichenbaum, M., and Fisher, J. (2003). 'Fiscal shocks and their consequences', Journal of Economic Theory, vol. 115, pp. 89-117.

[17] Chamley, C. (1986). 'Optimal taxation of capital income in general equilibrium with infinite lives', Econometrica, vol. 54, pp. 607-622.

[18] Chari, V., Lawrence, C and Kehoe, P. (1994). 'Optimal fiscal policy in a business cycle model', Journal of Political Economy, vol. 102, pp. 617-652.

[19] Chari, V. and Kehoe, P. (1999). 'Optimal fiscal and monetary policy', in J.B. Taylor \& M. Woodford (ed.), Handbook of Macroeconomics. Elsevier 1(26), 1671-1745.

[20] Chari, V., Kehoe, P. and McGrattan, E. (2002). 'Accounting for the great depression', American Economic Review, vol. 92, pp. 22-27.

[21] Chari, V., Kehoe, P. and McGrattan, E. (2007). 'Business cycle accounting', Econometrica, vol. 75, pp. 781-836.

[22] Conesa, J., Kitao, S. and Krueger, D. (2009). 'Taxing capital? not a bad idea after all!', American Economic Review, vol. 99, pp. 25-48.

[23] Cooley, T. and Hansen, G. (1992). 'Tax distortions in a neoclassical monetary economy', Journal of Economic Theory, vol. 58, pp. 290-316.

[24] Correia, I. (1996). 'Should capital income be taxed in the steady state?', Journal of Public Economics, vol. 60, pp. 147-151.

[25] Daveri, F. and Maffezzoli, M. (2001). 'A numerical approach to fiscal policy, unemployment, and growth in Europe', Econometrics and Applied Economics Working Paper, Istituto di Economia Politica, Bocconi University, No. 4. 
[26] Domeij, D. (2005). 'Optimal capital taxation and labour market search', Review of Economic Dynamics, vol. 8, pp. 623-650.

[27] Finn, M. (1998). 'Cyclical effects of government's employment and goods purchases', International Economic Review, vol. 39, pp. 635-657.

[28] Gali, J., López-Salido, J. and Vallés, J. (2007). 'Understanding the effects of government spending on consumption', Journal of the European Economic Association, vol. 5, pp. 227-270.

[29] Guo, J. and Lansing, K (1999). 'Optimal taxation of capital income with Impefectly competitive product markets', Journal of Economic Dynamics and Control, vol. 23, pp. 967-995.

[30] Judd, K. (1985). 'Redistributive taxation in a simple perfect foresight model', Journal of Public Economics, vol. 28, pp. 59-83.

[31] Judd, K. (1997). 'The optimal tax on capital income is negative', NBER Working Paper, No. 6004.

[32] Judd, K. (1999). 'Optimal taxation and spending in general competitive growth models', Journal of Public Economics, vol. 71, pp. 1-26.

[33] Judd, K. (2002). 'Capital income taxation with imperfect competition', American Economic Review, vol. 92, pp. 417-421.

[34] Klein, P. (2000). 'Using the generalized schur form to solve a multivariate linear rational expectations model', Journal of Economic Dynamics and Control, vol. 24, pp. 1405-1423.

[35] Kormendi, R. (1983). 'Government debt, government spending, and private sector behavior', American Economics Review, vol. 73, pp. 9941010 .

[36] Koskela, E. and von Thadden, L. (2008). 'Optimal factor taxation under wage bargaining: a dynamic perspective', German Economic Review, vol. 9, pp. 135-159.

[37] Krusell, P. (2002). 'Time-consistent redistribution', European Economic Review, vol. 46, pp. 755-769.

[38] Lansing, K. (1999). 'Optimal redistributive capital taxation in a neoclassical growth model', Journal of Public Economics, vol. 73, pp. 423-453. 
[39] Ljungqvist, L. and Sargent, T. (2006). 'Do taxes explain European employment? Indivisible labor, human capital, lotteries, and savings', NBER Macroeconomics Annual, vol. 21, pp. 181-246.

[40] Lucas, R. (1990). 'Supply-side economics: an analytical review', Oxford Economic Papers, vol. 42, pp. 293-316.

[41] Malley, J., Philippopoulos, A. and Woitek, U. (2009) 'To react or not? Technology shocks, fiscal policy and welfare in the EU-3. European Economic Review, vol. 53, pp. 689-714.

[42] Mortensen, D. and Pissarides, C. (1994). 'Job creation and job destruction in the theory of unemployment', Review of Economic Studies, vol. 61, pp.397-415.

[43] Munnell, A. (1990). 'Why has productivity growth declined? productivity and public investment', Federal Reserve Bank of Boston, New England Economic Review, January/February, 3-22.

[44] Ohanian, L. (1997). 'The macroeconomic effects of war finance in the United States: World War II and the Korean War', American Economic Review, vol. 871, pp. 23-40.

[45] Pissarides, C. (1998). 'The impact of employment tax cuts on unemployment and wages; the role of unemployment benefits and tax structure', European Economic Review, vol. 42, pp. 155-183.

[46] Prescott, E. (2002). 'Prosperity and depression', American Economic Review, vol. 92, pp. 1-15.

[47] Prescott, E. (2004). 'Why do Americans work so much more than Europeans?', Quarterly Review, Federal Reserve Bank of Minneapolis, issue July, pp. 2-13.

[48] Shimer, R. (2009). 'Convergence in Macroeconomics: the labor wedge', American Economic Journal: Macroeconomics, vol. 1, pp. 280-297.

[49] Werning, I. (2007). 'Optimal fiscal policy with redistribution', The Quarterly Journal of Economics, vol. 122, pp. 925-967. 
Table 1: Model calibration

\begin{tabular}{llc}
\hline \hline Parameter & Definition & Value \\
\hline $0<\beta<1$ & rate of time preference & 0.970 \\
$0<\alpha_{1}<1$ & capital's share of output & 0.375 \\
$0<\alpha_{2}<1$ & labour's share of output & 0.600 \\
$0<\omega \leq 1$ & degree of substitutability & 0.400 \\
$0<\mu<1$ & weight of consumption & 0.850 \\
$0<\delta^{p}, \delta^{g}<1$ & depreciation rate on capital & 0.100 \\
$0<n^{k}<1$ & population share of capitalists & 0.115 \\
$\sigma>0$ & elasticity of substitution & 2.000 \\
$A>0$ & TFP & 1.000 \\
$0 \leq \tau^{k}<1$ & tax rate on capital income & 0.344 \\
$0 \leq \tau^{w}<1$ & tax rate on labour income & 0.188 \\
$0 \leq \bar{r}<1$ & replacement rate & 0.204 \\
$0 \leq g^{i}<1$ & public investment-to-output ratio & 0.025 \\
\hline
\end{tabular}

Table 2: Data averages and model's steady-state values

\begin{tabular}{ccc}
\hline \hline Variable & Data average & Model \\
\hline$K^{k} / Y$ & 2.720 & 2.549 \\
$I^{k} / Y$ & 0.201 & 0.255 \\
$C / Y$ & 0.597 & 0.592 \\
$G^{c} / Y$ & 0.202 & 0.129 \\
$H^{w}$ & 0.930 & 0.930 \\
\hline
\end{tabular}


Table 3: Steady state of optimal policy

\begin{tabular}{ccccc}
\hline \hline & \multicolumn{2}{c}{$\pi_{t}^{k}=0$} & \multicolumn{2}{c}{$\pi_{t}^{k} \neq 0$} \\
Variable & Exogenous & Ramsey & Exogenous & Ramsey \\
\hline$C^{k}$ & 1.172 & 1.495 & 1.154 & 1.639 \\
$K^{k}$ & 37.895 & 48.332 & 30.892 & 40.472 \\
$I^{k}$ & 3.790 & 4.833 & 3.089 & 4.047 \\
$C^{w}$ & 0.899 & 0.966 & 0.782 & 0.813 \\
$H^{w}$ & 0.930 & 0.976 & 0.930 & 0.976 \\
$Y^{f}$ & 13.940 & 15.820 & 12.122 & 13.760 \\
$K^{k} / Y$ & 2.720 & 3.055 & 2.549 & 2.941 \\
$I^{k} / Y$ & 0.272 & 0.306 & 0.255 & 0.294 \\
$K^{g} / Y$ & 0 & 0 & 0.250 & 0.189 \\
$I^{g} / Y$ & 0 & 0 & 0.025 & 0.019 \\
$C / Y$ & 0.580 & 0.564 & 0.592 & 0.574 \\
$G^{c} / Y$ & 0.148 & 0.130 & 0.129 & 0.113 \\
$r$ & 0.147 & 0.131 & 0.147 & 0.128 \\
$w$ & 1.168 & 1.263 & 1.016 & 1.099 \\
$\tau^{k}$ & 0.344 & 0 & 0.344 & -0.125 \\
$\tau^{w}$ & 0.188 & 0.212 & 0.188 & 0.237 \\
$\bar{r}$ & 0.204 & -0.212 & 0.204 & -0.226 \\
$U^{k}$ & 1.222 & 1.487 & 1.191 & 1.592 \\
$U^{w}$ & 0.776 & 0.794 & 0.680 & 0.676 \\
$U$ & 0.827 & 0.873 & 0.739 & 0.782 \\
\hline & & & &
\end{tabular}


Table 4: Non-Benthamite government $\left(\pi_{t}^{k}=0\right)$

\begin{tabular}{ccccccc}
\hline \hline & $\gamma=0$ & $\gamma=0.105$ & $\gamma=0.110$ & $\gamma=\mathbf{0 . 1 1 5}$ & $\gamma=0.120$ & $\gamma=0.125$ \\
& $(1)$ & $(2)$ & $(3)$ & $\mathbf{( 4 )}$ & $(5)$ & $(6)$ \\
\hline$C^{k}$ & 1.495 & 1.495 & 1.495 & $\mathbf{1 . 4 9 5}$ & 1.495 & 1.495 \\
$C^{w}$ & 0.966 & 0.966 & 0.966 & $\mathbf{0 . 9 6 6}$ & 0.966 & 0.966 \\
$H^{w}$ & 0.976 & 0.976 & 0.976 & $\mathbf{0 . 9 7 6}$ & 0.976 & 0.976 \\
$\tau^{k}$ & 0.000 & 0.000 & 0.000 & $\mathbf{0 . 0 0 0}$ & 0.000 & 0.000 \\
$\tau^{w}$ & 0.212 & 0.212 & 0.212 & $\mathbf{0 . 2 1 2}$ & 0.212 & 0.212 \\
$\bar{r}$ & -0.212 & -0.212 & -0.212 & $\mathbf{- 0 . 2 1 2}$ & -0.212 & -0.212 \\
$U^{k}$ & 1.487 & 1.487 & 1.487 & $\mathbf{1 . 4 8 7}$ & 1.487 & 1.487 \\
$U^{w}$ & 0.794 & 0.794 & 0.794 & $\mathbf{0 . 7 9 4}$ & 0.794 & 0.794 \\
$U$ & 0.873 & 0.873 & 0.873 & $\mathbf{0 . 8 7 3}$ & 0.873 & 0.873 \\
\hline
\end{tabular}

Table 5: Non-Benthamite government $\left(\pi_{t}^{k} \neq 0\right)$

\begin{tabular}{ccccccc}
\hline \hline & $\gamma=0$ & $\gamma=0.105$ & $\gamma=0.110$ & $\boldsymbol{\gamma}=\mathbf{0 . 1 1 5}$ & $\gamma=0.120$ & $\gamma=0.125$ \\
& $(1)$ & $(2)$ & $(3)$ & $\mathbf{( 4 )}$ & $(5)$ & $(6)$ \\
\hline$C^{k}$ & 1.200 & 1.537 & 1.581 & $\mathbf{1 . 6 3 9}$ & 1.723 & 1.929 \\
$C^{w}$ & 0.827 & 0.819 & 0.817 & $\mathbf{0 . 8 1 3}$ & 0.807 & 0.789 \\
$H^{w}$ & 0.974 & 0.976 & 0.976 & $\mathbf{0 . 9 7 7}$ & 0.977 & 0.978 \\
$\tau^{k}$ & 0.342 & $2 \mathrm{E}-04$ & -0.053 & $\mathbf{- 0 . 1 2 5}$ & -0.236 & -0.539 \\
$\tau^{w}$ & 0.152 & 0.218 & 0.227 & $\mathbf{0 . 2 3 7}$ & 0.252 & 0.286 \\
$\bar{r}$ & -0.189 & -0.218 & -0.222 & $\mathbf{- 0 . 2 2 6}$ & -0.231 & -0.248 \\
$U^{k}$ & 1.229 & 1.508 & 1.544 & $\mathbf{1 . 5 9 2}$ & 1.660 & 1.828 \\
$U^{w}$ & 0.689 & 0.681 & 0.679 & $\mathbf{0 . 6 7 6}$ & 0.671 & 0.658 \\
$U$ & 0.751 & 0.776 & 0.778 & $\mathbf{0 . 7 8 2}$ & 0.785 & 0.792 \\
\hline
\end{tabular}

Table 6: Welfare losses/gains

\begin{tabular}{ccccccc}
\hline \hline & \multicolumn{2}{c}{ Capitalist $\left(\zeta^{k}\right)$} & \multicolumn{2}{c}{ Worker $\left(\zeta^{w}\right)$} & \multicolumn{3}{c}{$\begin{array}{c}\text { Aggregate }(\zeta) \\
(3)\end{array}$} \\
$\gamma$ & $\pi_{t}^{k} \neq 0$ & $\pi_{t}^{k}=0$ & $\pi_{t}^{k} \neq 0$ & $\pi_{t}^{k}=0$ & $\pi_{t}^{k} \neq 0$ & $\pi_{t}^{k}=0$ \\
\hline 0.000 & 0.040 & 0.276 & 0.014 & 0.028 & 0.017 & 0.052 \\
0.105 & 0.332 & 0.276 & 0.001 & 0.028 & 0.036 & 0.052 \\
0.110 & 0.370 & 0.276 & -0.003 & 0.028 & 0.039 & 0.052 \\
$\mathbf{0 . 1 1 5}$ & $\mathbf{0 . 4 2 0}$ & $\mathbf{0 . 2 7 6}$ & $\mathbf{- 0 . 0 0 8}$ & $\mathbf{0 . 0 2 8}$ & $\mathbf{0 . 0 4 3}$ & $\mathbf{0 . 0 5 2}$ \\
0.120 & 0.492 & 0.276 & -0.016 & 0.028 & 0.050 & 0.052 \\
0.125 & 0.671 & 0.276 & -0.038 & 0.028 & 0.061 & 0.052 \\
\hline
\end{tabular}


Figure 1: Non-Benthamite (partisan) preferences in the model with profits
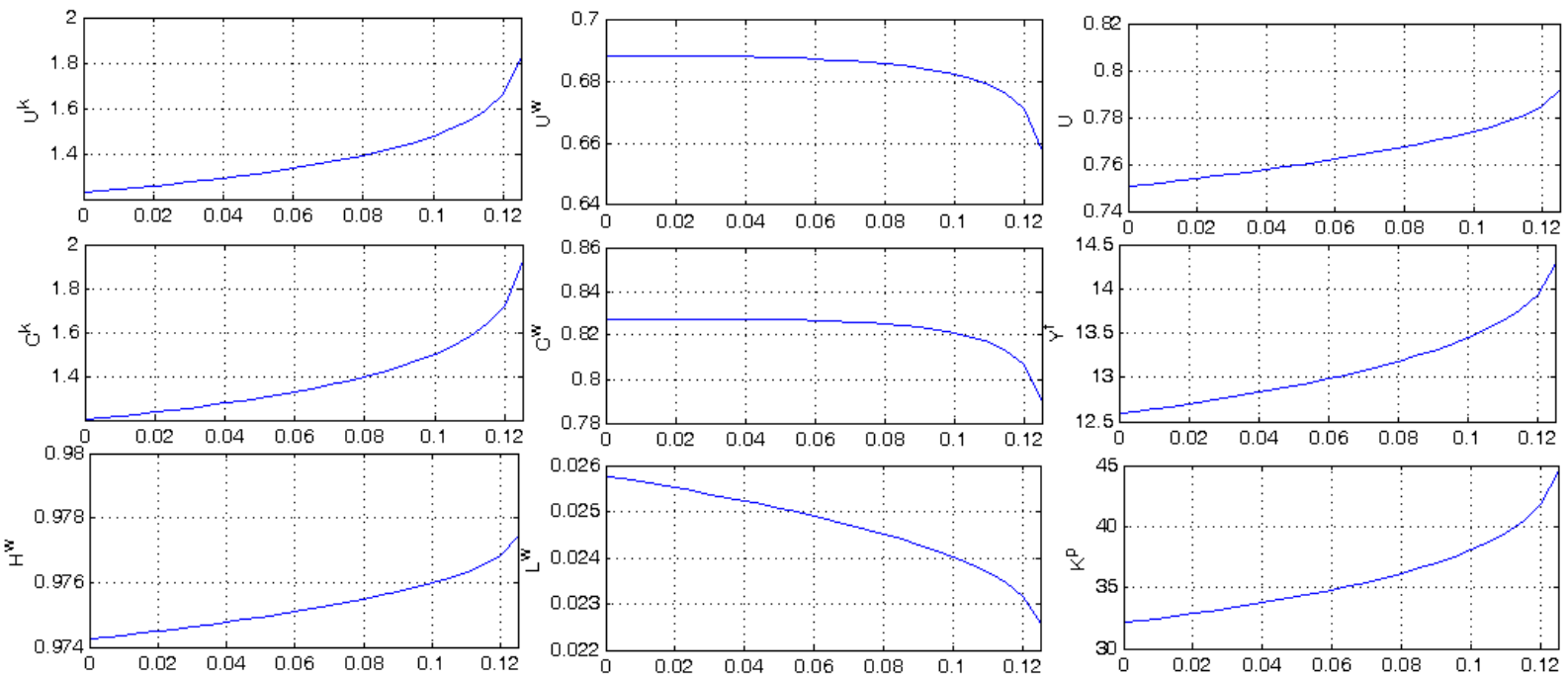

I
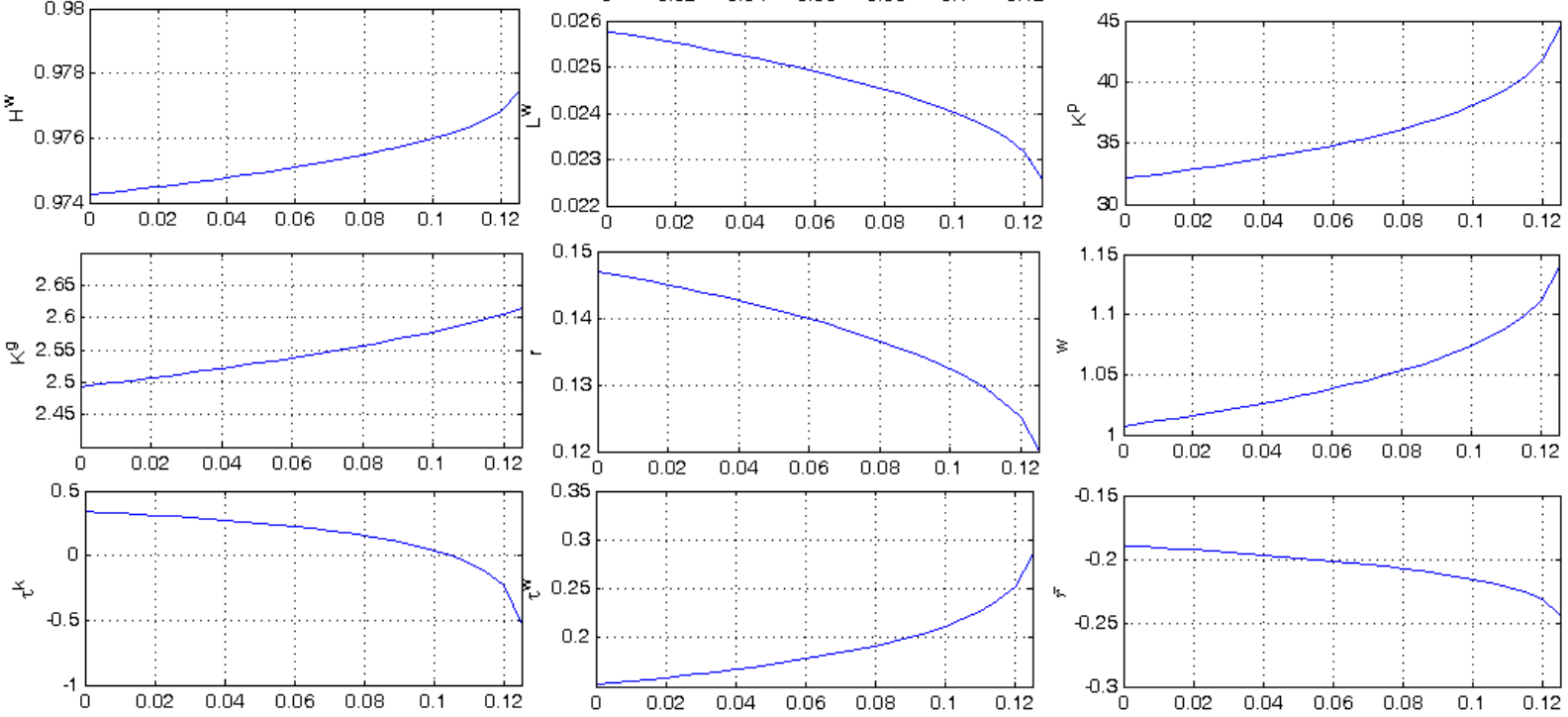


\section{Appendix}

\section{1 - Optimisation problem of capitalists}

The optimisation problem of the capitalist can be expressed mathematically as follows:

$$
\begin{gathered}
\max _{\left\{C_{t}^{k}, K_{t+1}^{k}\right\}_{t=0}^{\infty}}\left\{\sum_{t=0}^{\infty} \beta^{t}\left[\mu\left(C_{t}^{k}+\omega \bar{G}_{t}^{c}\right)^{\frac{\sigma-1}{\sigma}}+(1-\mu)(1-0)^{\frac{\sigma-1}{\sigma}}\right]^{\frac{\sigma}{\sigma-1}}\right\} \\
\text { s.t. } \quad C_{t}^{k}+K_{t+1}^{k}-\left(1-\delta^{p}\right) K_{t}^{k}=r_{t} K_{t}^{k}-\tau_{t}^{k}\left(r_{t}-\delta^{p}\right) K_{t}^{k} .
\end{gathered}
$$

The Lagrangian function of the capitalist is then written as:

$$
\begin{aligned}
& L^{k}=\sum_{t=0}^{\infty} \beta^{t}\left\{\left[\mu\left(C_{t}^{k}+\omega \bar{G}_{t}^{c}\right)^{\frac{\sigma-1}{\sigma}}+(1-\mu)(1-0)^{\frac{\sigma-1}{\sigma}}\right]^{\frac{\sigma}{\sigma-1}}+\right. \\
& \left.+\xi_{t}\left[r_{t} K_{t}^{k}-\tau_{t}^{k}\left(r_{t}-\delta^{p}\right) K_{t}^{k}-C_{t}^{k}-K_{t+1}^{k}+\left(1-\delta^{p}\right) K_{t}^{k}\right]\right\}
\end{aligned}
$$

where $\xi_{t}$ is the Lagrangian multiplier on the capitalist's budget constraint.

The first-order condition (FOC) for $C_{t}^{k}$ is:

$$
\left[\mu\left(C_{t}^{k}+\omega \bar{G}_{t}^{c}\right)^{\frac{\sigma-1}{\sigma}}+(1-\mu)\right]^{\frac{1}{\sigma-1}} \cdot \mu\left(C_{t}^{k}+\omega \bar{G}_{t}^{c}\right)^{-\frac{1}{\sigma}}=\xi_{t} .
$$

The FOC for $K_{t+1}^{k}$ is:

$$
\beta \xi_{t+1}\left[1+\left(1-\tau_{t+1}^{k}\right)\left(r_{t+1}-\delta^{p}\right)\right]=\xi_{t} .
$$

Consolidating these two FOCs yields the following equation:

$$
\begin{aligned}
& \left(C_{t}^{k}+\omega \bar{G}_{t}^{c}\right)^{-\frac{1}{\sigma}}\left[\mu\left(C_{t}^{k}+\omega \bar{G}_{t}^{c}\right)^{\frac{\sigma-1}{\sigma}}+(1-\mu)\right]^{\frac{1}{\sigma-1}} \\
= & \beta\left(C_{t+1}^{k}+\omega \bar{G}_{t+1}^{c}\right)^{-\frac{1}{\sigma}}\left[\mu\left(C_{t+1}^{k}+\omega \bar{G}_{t+1}^{c}\right)^{\frac{\sigma-1}{\sigma}}+(1-\mu)\right]^{\frac{1}{\sigma-1}} . \\
& \left.\cdot\left[1+\left(1-\tau_{t+1}^{k}\right)\left(r_{t+1}-\delta^{p}\right)\right]\right\} .
\end{aligned}
$$

\section{2 - Optimisation problem of workers}

The optimisation problem for the worker is shown as follows:

$$
\begin{gathered}
\max _{C_{t}^{w}, H_{t}^{w}}\left\{\left[\mu\left(C_{t}^{w}+\omega \bar{G}_{t}^{c}\right)^{\frac{\sigma-1}{\sigma}}+(1-\mu)\left(1-H_{t}^{w}\right)^{\frac{\sigma-1}{\sigma}}\right]^{\frac{\sigma}{\sigma-1}}\right\} \\
\text { s.t. } \quad C_{t}^{w}=\left(1-\tau_{t}^{w}\right) w_{t} H_{t}^{w}+\bar{G}_{t}^{u}\left(1-H_{t}^{w}\right) .
\end{gathered}
$$


The Lagrangian function of the worker is written as:

$$
\begin{aligned}
L^{w}= & {\left[\mu\left(C_{t}^{w}+\omega \bar{G}_{t}^{c}\right)^{\frac{\sigma-1}{\sigma}}+(1-\mu)\left(1-H_{t}^{w}\right)^{\frac{\sigma-1}{\sigma}}\right]^{\frac{\sigma}{\sigma-1}}+} \\
& +\phi_{t}\left[\left(1-\tau_{t}^{w}\right) w_{t} H_{t}^{w}+\bar{G}_{t}^{u}\left(1-H_{t}^{w}\right)-C_{t}^{w}\right]
\end{aligned}
$$

where $\phi_{t}$ is the Lagrangian multiplier on the worker's budget constraint.

The FOC for $C_{t}^{w}$ is:

$$
\left[\mu\left(C_{t}^{w}+\omega \bar{G}_{t}^{c}\right)^{\frac{\sigma-1}{\sigma}}+(1-\mu)\left(1-H_{t}^{w}\right)^{\frac{\sigma-1}{\sigma}}\right]^{\frac{1}{\sigma-1}} \mu\left(C_{t}^{w}+\omega \bar{G}_{t}^{c}\right)^{-\frac{1}{\sigma}}=\phi_{t} .
$$

The FOC for $H_{t}^{w}$ is:

$$
\begin{aligned}
{\left[\mu\left(C_{t}^{w}+\omega \bar{G}_{t}^{c}\right)^{\frac{\sigma-1}{\sigma}}\right.} & \left.+(1-\mu)\left(1-H_{t}^{w}\right)^{\frac{\sigma-1}{\sigma}}\right]^{\frac{1}{\sigma-1}}(\mu-1)\left(1-H_{t}^{w}\right)^{-\frac{1}{\sigma}}+ \\
& +\phi_{t}\left(1-\tau_{t}^{w}\right) w_{t}-\phi_{t} \bar{G}_{t}^{u}=0 .
\end{aligned}
$$

These two FOCs are next combined into one equation as follows:

$$
\begin{aligned}
& (1-\mu)\left(1-H_{t}^{w}\right)^{-\frac{1}{\sigma}}+\mu \bar{G}_{t}^{u}\left(C_{t}^{w}+\omega \bar{G}_{t}^{c}\right)^{-\frac{1}{\sigma}} \\
= & \mu w_{t}\left(1-\tau_{t}^{w}\right)\left(C_{t}^{w}+\omega \bar{G}_{t}^{c}\right)^{-\frac{1}{\sigma}}
\end{aligned}
$$

which can be re-written as:

$$
\begin{aligned}
& (1-\mu)\left(1-H_{t}^{w}\right)^{-\frac{1}{\sigma}}+\mu \bar{r}_{t} w_{t}\left(C_{t}^{w}+\omega \bar{G}_{t}^{c}\right)^{-\frac{1}{\sigma}} \\
= & \mu w_{t}\left(1-\tau_{t}^{w}\right)\left(C_{t}^{w}+\omega \bar{G}_{t}^{c}\right)^{-\frac{1}{\sigma}}
\end{aligned}
$$

\section{3 - Optimisation problem of firms}

The optimization problem for the firm can be summarized in the following:

$$
\begin{gathered}
\max _{K_{t}^{f}, N_{t}^{f}}\left\{Y_{t}^{f}-r_{t} K_{t}^{f}-w_{t} H_{t}^{f}\right\} \\
\text { s.t. } \quad Y_{t}^{f}=A\left(K_{t}^{f}\right)^{\alpha_{1}}\left(H_{t}^{f}\right)^{\alpha_{2}} .
\end{gathered}
$$

The Lagrangian function of the firm is written as:

$$
L^{f}=A\left(K_{t}^{f}\right)^{\alpha_{1}}\left(H_{t}^{f}\right)^{\alpha_{2}}-r_{t} K_{t}^{f}-w_{t} H_{t}^{f} .
$$


The FOC for $K_{t}^{f}$ is:

$$
\begin{gathered}
\alpha_{1} A\left(K_{t}^{f}\right)^{\alpha_{1}-1}\left(H_{t}^{f}\right)^{\alpha_{2}}-r_{t}=0 \\
r_{t}=\alpha_{1} A\left(K_{t}^{f}\right)^{\alpha_{1}-1}\left(H_{t}^{f}\right)^{\alpha_{2}}
\end{gathered}
$$

The FOC for $H_{t}^{f}$ is:

$$
\begin{gathered}
\alpha_{2} A\left(K_{t}^{f}\right)^{\alpha_{1}}\left(H_{t}^{f}\right)^{\alpha_{2}-1}-w_{t}=0 \\
w_{t}=\alpha_{2} A\left(K_{t}^{f}\right)^{\alpha_{1}}\left(H_{t}^{f}\right)^{\alpha_{2}-1}
\end{gathered}
$$

\section{4 - The DCE conditions}

The DCE consists of the following conditions:

$$
\begin{aligned}
& O C^{k}:\left(C_{t}^{k}+\omega \bar{G}_{t}^{c}\right)^{-\frac{1}{\sigma}}\left[\mu\left(C_{t}^{k}+\omega \bar{G}_{t}^{c}\right)^{\frac{\sigma-1}{\sigma}}+(1-\mu)\right]^{\frac{1}{\sigma-1}} \\
& =\beta\left(C_{t+1}^{k}+\omega \bar{G}_{t+1}^{c}\right)^{-\frac{1}{\sigma}}\left[\mu\left(C_{t+1}^{k}+\omega \bar{G}_{t+1}^{c}\right)^{\frac{\sigma-1}{\sigma}}+(1-\mu)\right]^{\frac{1}{\sigma-1}} \text {. } \\
& \cdot\left[1+\left(1-\tau_{t+1}^{k}\right)\left(r_{t+1}-\delta^{p}\right)\right] \\
& O C^{w}:(1-\mu)\left(1-H_{t}^{w}\right)^{-\frac{1}{\sigma}}+\mu \bar{r}_{t} w_{t}\left(C_{t}^{w}+\omega \bar{G}_{t}^{c}\right)^{-\frac{1}{\sigma}} \\
& =\mu w_{t}\left(1-\tau_{t}^{w}\right)\left(C_{t}^{w}+\omega \bar{G}_{t}^{c}\right)^{-\frac{1}{\sigma}} \\
& F O^{k}: r_{t}=\alpha_{1} A\left(K_{t}^{f}\right)^{\alpha_{1}-1}\left(H_{t}^{f}\right)^{\alpha_{2}}\left(\bar{K}_{t}^{g}\right)^{\alpha_{3}} \\
& F O^{l}: w_{t}=\alpha_{2} A\left(K_{t}^{f}\right)^{\alpha_{1}}\left(H_{t}^{f}\right)^{\alpha_{2}-1}\left(\bar{K}_{t}^{g}\right)^{\alpha_{3}} \\
& B C^{k}: C_{t}^{k}+K_{t+1}^{k}-\left(1-\delta^{p}\right) K_{t}^{k}=r_{t} K_{t}^{k}-\tau_{t}^{k}\left(r_{t}-\delta^{p}\right) K_{t}^{k} \\
& B C^{w}: C_{t}^{w}=\left(1-\tau_{t}^{w}\right) w_{t} H_{t}^{w}+\bar{r}_{t} w_{t}\left(1-H_{t}^{w}\right) \\
& B C^{g}: \bar{G}_{t}^{c}+\left(1-n^{k}\right) \bar{r}_{t} w_{t}\left(1-H_{t}^{w}\right)+n^{k} \bar{I}_{t}^{g} \\
& =n^{k}\left[\tau_{t}^{k}\left(r_{t}-\delta^{p}\right) K_{t}^{k}+\tau_{t}^{k} \pi_{t}^{k}\right]+\left(1-n^{k}\right) \tau_{t}^{w} w_{t} H_{t}^{w} \\
& P C^{g}: \bar{K}_{t+1}^{g}=\left(1-\delta^{g}\right) \bar{K}_{t}^{g}+\bar{I}_{t}^{g} \\
& M C^{k}: K_{t}^{k}=K_{t}^{f} \\
& M C^{l}: H_{t}^{w}=\frac{n^{k}}{\left(1-n^{k}\right)} H_{t}^{f}
\end{aligned}
$$




\section{5 - Derivation of $\zeta^{i}$}

$\zeta^{i}$ satisfies the follow equation implying that the agent $i$ is as well off in the exogenous policy model as in the Ramsey model.

$$
U_{R}^{i}=\bar{U}_{E}^{i}=\left[\mu\left(C_{E}^{i}\left(1+\zeta^{i}\right)+\omega \bar{G}_{E}^{c}\right)^{\frac{\sigma-1}{\sigma}}+(1-\mu)\left(1-H_{E}^{i}\right)^{\frac{\sigma-1}{\sigma}}\right]^{\frac{\sigma}{\sigma-1}}
$$

We can solve for $\zeta^{i}$ in the equation above by taking the following algebra:

$$
\begin{gathered}
\left(U_{R}^{i}\right)^{\frac{\sigma-1}{\sigma}}=\left[\mu\left(C_{E}^{i}\left(1+\zeta^{i}\right)+\omega \bar{G}_{E}^{c}\right)^{\frac{\sigma-1}{\sigma}}+(1-\mu)\left(1-H_{E}^{i}\right)^{\frac{\sigma-1}{\sigma}}\right]^{\frac{\sigma}{\sigma-1} \cdot \frac{\sigma-1}{\sigma}} \\
\left(U_{R}^{i}\right)^{\frac{\sigma-1}{\sigma}}=\mu\left(C_{E}^{i}\left(1+\zeta^{i}\right)+\omega \bar{G}_{E}^{c}\right)^{\frac{\sigma-1}{\sigma}}+(1-\mu)\left(1-H_{E}^{i}\right)^{\frac{\sigma-1}{\sigma}} \\
\left(U_{R}^{i}\right)^{\frac{\sigma-1}{\sigma}}-(1-\mu)\left(1-H_{E}^{i}\right)^{\frac{\sigma-1}{\sigma}}=\mu\left(C_{E}^{i}\left(1+\zeta^{i}\right)+\omega \bar{G}_{E}^{c}\right)^{\frac{\sigma-1}{\sigma}} \\
{\left[\left(U_{R}^{i}\right)^{\frac{\sigma-1}{\sigma}}-(1-\mu)\left(1-H_{E}^{i}\right)^{\frac{\sigma-1}{\sigma}}\right]^{\frac{\sigma}{\sigma-1}}=\left[\mu\left(C_{E}^{i}\left(1+\zeta^{i}\right)+\omega \bar{G}_{E}^{c}\right)^{\frac{\sigma-1}{\sigma}}\right]^{\frac{\sigma}{\sigma-1}}} \\
{\left[\left(U_{R}^{i}\right)^{\frac{\sigma-1}{\sigma}}-(1-\mu)\left(1-H_{E}^{i}\right)^{\frac{\sigma-1}{\sigma}}\right]^{\frac{\sigma}{\sigma-1}}=\mu^{\frac{\sigma}{\sigma-1}}\left[C_{E}^{i}\left(1+\zeta^{i}\right)+\omega \bar{G}_{E}^{c}\right]} \\
{\left[\left(U_{R}^{i}\right)^{\frac{\sigma-1}{\sigma}}-(1-\mu)\left(1-H_{E}^{i}\right)^{\frac{\sigma-1}{\sigma}}\right]^{\frac{\sigma}{\sigma-1}} \mu^{\frac{\sigma}{1-\sigma}}=C_{E}^{i}\left(1+\zeta^{i}\right)+\omega \bar{G}_{E}^{c}} \\
{\left[\left(U_{R}^{i}\right)^{\frac{\sigma-1}{\sigma}}-(1-\mu)\left(1-H_{E}^{i}\right)^{\frac{\sigma-1}{\sigma}}\right]^{\frac{\sigma}{\sigma-1}} \mu^{\frac{\sigma}{1-\sigma}}-\omega \bar{G}_{E}^{c}=C_{E}^{i}\left(1+\zeta^{i}\right)} \\
{\left[\left(U_{R}^{i}\right)^{\frac{\sigma-1}{\sigma}}-(1-\mu)\left(1-H_{E}^{i}\right)^{\frac{\sigma-1}{\sigma}}\right]^{\frac{\sigma}{\sigma-1}} \mu^{\frac{\sigma}{1-\sigma}}-\omega \bar{G}_{E}^{c}} \\
\quad C_{E}^{i}=1+\zeta^{i} . \\
\Rightarrow \zeta^{i}=\frac{\left[\left(U_{R}^{i}\right)^{\frac{\sigma-1}{\sigma}}-(1-\mu)\left(1-H_{E}^{i}\right)^{\frac{\sigma-1}{\sigma}}\right]^{\frac{\sigma}{\sigma-1}} \mu \frac{\sigma}{1-\sigma}-\omega \bar{G}_{E}^{c}}{C_{E}^{i}}-1
\end{gathered}
$$




\section{5 - Derivation of $\zeta^{i}$}

$\zeta^{i}$ satisfies the follow equation implying that the agent $i$ is as well off in the exogenous policy model as in the Ramsey model.

$$
U_{R}^{i}=\bar{U}_{E}^{i}=\left[\mu\left(C_{E}^{i}\left(1+\zeta^{i}\right)+\omega \bar{G}_{E}^{c}\right)^{\frac{\sigma-1}{\sigma}}+(1-\mu)\left(1-H_{E}^{i}\right)^{\frac{\sigma-1}{\sigma}}\right]^{\frac{\sigma}{\sigma-1}}
$$

We can solve for $\zeta^{i}$ in the equation above by taking the following algebra:

$$
\begin{gathered}
\left(U_{R}^{i}\right)^{\frac{\sigma-1}{\sigma}}=\left[\mu\left(C_{E}^{i}\left(1+\zeta^{i}\right)+\omega \bar{G}_{E}^{c}\right)^{\frac{\sigma-1}{\sigma}}+(1-\mu)\left(1-H_{E}^{i}\right)^{\frac{\sigma-1}{\sigma}}\right]^{\frac{\sigma}{\sigma-1} \cdot \frac{\sigma-1}{\sigma}} \\
\left(U_{R}^{i}\right)^{\frac{\sigma-1}{\sigma}}=\mu\left(C_{E}^{i}\left(1+\zeta^{i}\right)+\omega \bar{G}_{E}^{c}\right)^{\frac{\sigma-1}{\sigma}}+(1-\mu)\left(1-H_{E}^{i}\right)^{\frac{\sigma-1}{\sigma}} \\
\left(U_{R}^{i}\right)^{\frac{\sigma-1}{\sigma}}-(1-\mu)\left(1-H_{E}^{i}\right)^{\frac{\sigma-1}{\sigma}}=\mu\left(C_{E}^{i}\left(1+\zeta^{i}\right)+\omega \bar{G}_{E}^{c}\right)^{\frac{\sigma-1}{\sigma}} \\
{\left[\left(U_{R}^{i}\right)^{\frac{\sigma-1}{\sigma}}-(1-\mu)\left(1-H_{E}^{i}\right)^{\frac{\sigma-1}{\sigma}}\right]^{\frac{\sigma}{\sigma-1}}=\left[\mu\left(C_{E}^{i}\left(1+\zeta^{i}\right)+\omega \bar{G}_{E}^{c}\right)^{\frac{\sigma-1}{\sigma}}\right]^{\frac{\sigma}{\sigma-1}}} \\
{\left[\left(U_{R}^{i}\right)^{\frac{\sigma-1}{\sigma}}-(1-\mu)\left(1-H_{E}^{i}\right)^{\frac{\sigma-1}{\sigma}}\right]^{\frac{\sigma}{\sigma-1}}=\mu^{\frac{\sigma}{\sigma-1}}\left[C_{E}^{i}\left(1+\zeta^{i}\right)+\omega \bar{G}_{E}^{c}\right]} \\
{\left[\left(U_{R}^{i}\right)^{\frac{\sigma-1}{\sigma}}-(1-\mu)\left(1-H_{E}^{i}\right)^{\frac{\sigma-1}{\sigma}}\right]^{\frac{\sigma}{\sigma-1}} \mu^{\frac{\sigma}{1-\sigma}}=C_{E}^{i}\left(1+\zeta^{i}\right)+\omega \bar{G}_{E}^{c}} \\
{\left[\left(U_{R}^{i}\right)^{\frac{\sigma-1}{\sigma}}-(1-\mu)\left(1-H_{E}^{i}\right)^{\frac{\sigma-1}{\sigma}}\right]^{\frac{\sigma}{\sigma-1}} \mu^{\frac{\sigma}{1-\sigma}}-\omega \bar{G}_{E}^{c}=C_{E}^{i}\left(1+\zeta^{i}\right)} \\
{\left[\left(U_{R}^{i}\right)^{\frac{\sigma-1}{\sigma}}-(1-\mu)\left(1-H_{E}^{i}\right)^{\frac{\sigma-1}{\sigma}}\right]^{\frac{\sigma}{\sigma-1}} \mu^{\frac{\sigma}{1-\sigma}}-\omega \bar{G}_{E}^{c}} \\
\quad C_{E}^{i}=1+\zeta^{i} . \\
\Rightarrow \zeta^{i}=\frac{\left[\left(U_{R}^{i}\right)^{\frac{\sigma-1}{\sigma}}-(1-\mu)\left(1-H_{E}^{i}\right)^{\frac{\sigma-1}{\sigma}}\right]^{\frac{\sigma}{\sigma-1}} \mu \frac{\sigma}{1-\sigma}-\omega \bar{G}_{E}^{c}}{C_{E}^{i}}-1
\end{gathered}
$$

